\title{
Culturally Grounded Indicators of Resilience in Social-Ecological Systems
}

\author{
Eleanor Sterling, Tamara Ticktin, Tē Kipa Kepa Morgan, Georgina Cullman, \\ Diana Alvira, Pelika Andrade, Nadia Bergamini, Erin Betley, Kate Burrows, \\ Sophie Caillon, Joachim Claudet, Rachel Dacks, Pablo Eyzaguirre, Chris Filardi, \\ Nadav Gazit, Christian Giardina, Stacy Jupiter, Kealohanuiopuna Kinney, \\ Joe McCarter, Manuel Mejia, Kanoe Morishige, Jennifer Newell, Lihla Noori, \\ John Parks, Pua'ala Pascua, Ashwin Ravikumar, Jamie Tanguay, \\ Amanda Sigouin, Tina Stege, Mark Stege, and Alaka Wali'
}

ABSTRACT: Measuring progress toward sustainability goals is a multifaceted task. International, regional, and national organizations and agencies seek to promote resilience and capacity for adaptation at local levels. However, their measurement systems may be poorly aligned with local contexts, cultures, and needs. Understanding how to build effective, culturally grounded measurement systems is a fundamental step toward supporting adaptive management and resilience in the face of environmental, social, and economic change. To identify patterns and inform future efforts, we review seven case studies and one framework regarding the development of culturally grounded indicator sets. Additionally, we explore ways to bridge locally relevant indicators and those of use at national and international levels. The process of identifying and setting criteria for appropriate indicators of resilience in social-ecological systems needs further documentation, discussion, and refinement, particularly regarding capturing feedbacks between biological and social-cultural elements of systems.

KEYWORDS: biocultural indicators, indicator sets, Indigenous Peoples, local communities, resilience, sustainability, well-being

Indigenous and other place-based, local communities increasingly face an assortment of externally codified development and sustainability goals, regional commitments, and national policies and actions that are designed, in part, to foster adaptation and resilience at the local level. Resilience refers to the capacity of a system to absorb shocks and disturbances and to catalyze renewal, adaptation, transformation, and innovation (Béné et al. 2013). Identifying and setting criteria for the underlying factors that confer resilience to a community are the first steps toward effectively aligning external sustainability-seeking processes, often associated with resourcing mechanisms, with locally relevant and locally embraced approaches to sustaining environmental health and community well-being in the face of environmental, social, and economic change (Fazey et al. 2011; Folke et al. 2003). 
Here we present case studies on locally grounded indicators of resilience that include both social-cultural (institutions, networks, knowledge systems) and ecological (biodiversity, habitat, ecosystem services) components and their combined ability to respond to disturbances (Gunderson and Holling 2002). "Measuring" social-ecological resilience is particularly challenging, because neither organizational processes nor ecological processes can be understood in isolation (Olsson et al. 2004). For example, conventional indicators of ecosystem health (species richness, soil fertility, etc.) are not designed to capture dimensions of individual and community well-being, only rarely provide historical depth, and are not designed to engage traditional knowledge that can provide practical insights into local ecology or the social-cultural interactions that often govern ecosystem functioning and resilience (van Oudenhoven et al. 2011).

Indicator sets typically seek to provide credible qualitative or quantitative data-driven insights that allow for better understanding of a system while distilling complexity. Trend and state indicators are widely used by a range of entities - from nongovernmental organizations (NGOs) and local governments to international governing bodies-to track change within and across complex systems, identify stabilizing processes and drivers of positive or negative change, inform management and planning, and communicate patterns to constituents, managers, and policy makers. Further, indicator sets can measure the status of resources units, resources systems, or governance systems and actors in a social-ecological systems framework (SES) (Ostrom 2009) or measure relational elements within a framework (e.g., a driving forces, pressures, states, impacts, responses framework, or DPSIR) (Sparks et al. 2011).

Indicator sets are grounded in a vision or plan that forms the basis for responses to important questions such as indicators for whom, about what, and toward which goals. Externally developed goals, targets, and indicators, such as those associated with the United Nations (UN) Millennium Development Goals and the Sustainable Development Goals, are intended for use at high levels and, by necessity, are general. Goals, targets, and indicators influence a range of scales, including local contexts. For example, the near-universal use of economic indicators based on gross domestic product (GDP) often drives policies that promote material progress over the less tangible "well-being." As a result, such initiatives may prescribe actions to increase GDP with limited benefit for, or negative impact on, local communities (Cochran et al. 2008).

Elsewhere we have argued that in situ, culturally grounded approaches to developing indicators of human well-being and coupled ecological resilience-what we term biocultural approaches-can lead to effective local action as well as communication about local needs to national and international actors (Sterling et al. forthcoming). Ideally, when local communities are involved in indicator development, they create or co-create indicators that capture the social, cultural, and environmental context for managing coupled human and natural systems (Ens 2012; Preuss and Dixon 2012). Locally developed indicators and criteria greatly facilitate local understanding of their development and use, and therefore may also increase community ownership, adoption, and acceptance. Locally tailored metrics also present challenges, including the potential time commitment, costs, and feasibility involved in the process of developing and monitoring such metrics.

In this article, we assess seven case studies and one model framework for in situ, culturally grounded indicator development to derive broadly relevant insights and lessons learned for future indicator development. Each contribution was written by authors who were part of an indicator or framework development process; additionally, some authors assessed indicators through community focus groups, ran programs to support and expand the use of the indicators, and/or used the indicators in their research and management. Case study and framework authors addressed guiding elements shown in Table 1 and were encouraged to share any unique attributes of their case studies. 
Table 1: Guiding Elements for Case Study and Framework Authors

\begin{tabular}{|l|l|}
\hline \multirow{3}{*}{ Authorship } & Who developed indicator set? \\
\cline { 2 - 3 } & Author(s)' relationship to the case study \\
\hline \multirow{3}{*}{ Development process } & What catalyzed development of indicator set? For whom was it developed? \\
\cline { 2 - 3 } & Indicator set's primary objective (e.g., measuring well-being) \\
\hline & Where was indicator set developed? \\
\cline { 2 - 3 } & How were indicators developed? \\
\hline \multirow{5}{*}{ Standardization } & Total number of indicators (if applicable) \\
\cline { 2 - 3 } & $\begin{array}{l}\text { What indicator domains are assessed (e.g., environmental, social/cultural, } \\
\text { political/governance) }\end{array}$ \\
\cline { 2 - 3 } & Level of indicator focus (e.g., household, community, national) \\
\cline { 2 - 3 } & How is data collected and by whom? \\
\hline Applicability & Methods of standardization (if any) \\
\cline { 2 - 3 } & Is indicator set regionally specific or more broadly applicable? \\
\hline & Where has indicator set been applied? \\
\cline { 2 - 3 } & How is indicator set relevant to local decision makers? \\
\cline { 2 - 2 } & How has indicator set been used in decision making? \\
\hline
\end{tabular}

The authors of these contributions are among the leaders in implementing practical approaches to resource management using techniques that span social and ecological characteristics of a system; many have not yet published extensively on these practical experiences. All of these contributions describe initiatives that are "biocultural," meaning they take an approach strongly grounded in local culture and values for understanding and managing social-ecological systems. The majority of the initiatives presented here have been developed within social-ecological systems in Pacific Island environments. However, the lessons learned can be applied more broadly.

\section{Case Study Contributions}

\section{Indicators of Resilience in Socio-Ecological Production Landscapes and Seascapes} Nadia Bergamini and Pablo Eyzaguirre

This indicator set is intended for use at the community level, was designed for use in diverse settings, and has been used across the world. Its outcomes are geared toward social-ecological production landscapes and seascapes. The term "social-ecological production landscapes and seascapes," or SEPLS, was coined under the Satoyama Initiative to refer to mosaic production landscapes, which have been shaped through long-term harmonious interactions between humans and nature in a manner that fosters human well-being while maintaining biodiversity and ecosystem services (Gu and Subramanian 2012). Monitoring of natural resource management practices and how these adjust to changing conditions can contribute to evaluation of the resilience of SEPLS.

Through an iterative process of indicator development-which included on-the-ground testing to capture each community's priority elements of resilience and consultation with community members, local NGOs, and research institutes to ensure that local views and values 
were properly captured-a suite of researchers from international organizations designed 20 indicators to measure a community's capacity to build resilience and harness ecosystem services through innovation, adaptation, and the sustainable use of biodiversity (Mijatović et al. 2013; UNU-IAS et al. 2014; van Oudenhoven et al. 2011). The indicators cover the cultural, social, economic, ecological, and agricultural dimensions that influence, in positive or negative ways, biodiversity maintenance and therefore resilience in SEPLS. They can be customized to reflect the circumstances of each particular landscape and its associated communities. They encompass both qualitative and quantifiable indicators based on observations, tallies, perceptions, desires, visions, and experiences of local communities. The indicators do not provide precise measurements of resilience but rather serve as a framework for communities to discuss and analyze SEPLS resilience, and build community sense of ownership over landscape planning by incorporating biocultural views.

The spatial scale of SEPLS encompassed by the indicators depends on how local communities identify the area they depend on for their survival and livelihoods. It generally includes the mosaic of land uses from which communities derive the goods and services on which they depend directly or indirectly and where they have a direct impact on the resource base and regular interaction with biodiversity. The indicators are grouped into five areas (Table 2): SEPLS resilience and landscape/seascape diversity (Colding et al. 2003), biodiversity (Thaman et al. 2002), knowledge and innovation (Folke et al. 2003), governance and equity (Lebel et al. 2006), and livelihoods and well-being (Adger 2000).

These indicators may be adapted to and applied in different areas and can be used alongside other types of indicators. The ways in which social-ecological indicators are employed by communities, policy makers, and external scientists may differ. Indigenous communities may use them to monitor the impacts of conservation projects on traditional livelihoods and lifeways, or, once a "baseline" has been established, to monitor at regular intervals socialecological dynamics and define priorities for community and conservation action. Lessons and knowledge generated by these activities can then be used by communities to communicate local visions and strategies for resilient SEPLS as input for higher-level policies and programs that affect community livelihoods, as well as further conservation and resource-management planning. Policy makers in turn can use the results to promote participatory SEPLS landscape management among different stakeholders and identify an integrated approach in project planning and implementation. The indicators and biocultural approach can deepen Western scientific understanding of human-environment interactions and how these may be supported in a conservation context.

These indicators have been piloted across varied ecosystems in more than 25 different SEPLS in several countries. While refining the indicators, it was sometimes difficult to predict the overall sustainability of a given agroecosystem and measure the direct effects of management practices on ecosystem services. In this regard, Western knowledge can be applied in synergy with traditional knowledge systems. The goal is to learn from and strengthen the innovation present in traditional approaches to managing productive landscapes, not to support the marginalization or fossilizing of traditional lifestyles. The designers of the indicator set developed a dedicated tool kit for facilitators to conduct resilience assessments, which consists of a preparation stage, an assessment workshop, and a follow-up stage. During the preparation stage, facilitators obtain information about the SEPLS and plan the community based-resilience assessment workshop. During the assessment workshop, 10 to 15 community members of mixed age and gender come together to score the 20 indicators and provide their perception on trends (i.e., improving, no change, worsening) over a time span of 5 to 20 years. Scoring is first done individually and then as a group. The group discussion is important to both identifying different views within the community, and in reaching a common understanding of the SEPLS state, 
Table 2: Indicators of Resilience in Socio-Ecological Production Landscapes and Seascapes (SEPLS)

\begin{tabular}{|c|c|}
\hline Indicators & Questions for scoring \\
\hline \multicolumn{2}{|c|}{ Landscape/seascape diversity and ecosystem protection } \\
\hline (1) Landscape/seascape diversity & $\begin{array}{l}\text { Is the landscape/seascape composed of diverse natural ecosystems } \\
\text { (terrestrial and aquatic) and land uses? }\end{array}$ \\
\hline (2) Ecosystem protection & $\begin{array}{l}\text { Are there areas in the landscape or seascape where ecosystems are } \\
\text { protected under formal or informal forms of protection? }\end{array}$ \\
\hline $\begin{array}{l}\text { (3) Ecological interactions between } \\
\text { different components of the } \\
\text { landscape/seascape }\end{array}$ & $\begin{array}{l}\text { Are ecological interactions between different components of the } \\
\text { landscape or seascape considered while managing natural resources? }\end{array}$ \\
\hline $\begin{array}{l}\text { (4) Recovery and regeneration of the } \\
\text { landscape/seascape }\end{array}$ & $\begin{array}{l}\text { Does the landscape or seascape have the ability to recover and regenerate } \\
\text { after extreme environmental shocks? }\end{array}$ \\
\hline \multicolumn{2}{|l|}{ Biodiversity } \\
\hline (5) Diversity of local food system & Does the community consume a diversity of locally produced food? \\
\hline $\begin{array}{l}\text { (6) Maintenance and use of local } \\
\text { crop varieties and animal breeds }\end{array}$ & $\begin{array}{l}\text { Are different local crops, varieties, and animal breeds conserved and } \\
\text { used in the community? }\end{array}$ \\
\hline $\begin{array}{l}\text { (7) Sustainable management of } \\
\text { common resources }\end{array}$ & Are common resources managed sustainably? \\
\hline \multicolumn{2}{|l|}{ Knowledge and innovation } \\
\hline $\begin{array}{l}\text { (8) Innovation in agriculture and } \\
\text { conservation practices }\end{array}$ & $\begin{array}{l}\text { Does the community develop, improve, and adopt new agricultural, } \\
\text { fisheries, forestry, and conservation practices and/or revitalize traditional } \\
\text { ones to adapt to changing conditions, including climate change? }\end{array}$ \\
\hline $\begin{array}{l}\text { (9) Traditional knowledge related to } \\
\text { biodiversity }\end{array}$ & $\begin{array}{l}\text { Are local knowledge and cultural traditions related to biodiversity } \\
\text { transmitted from elders and parents to young people in the community? }\end{array}$ \\
\hline $\begin{array}{l}\text { (10) Documentation of biodiversity- } \\
\text { associated knowledge }\end{array}$ & $\begin{array}{l}\text { Is agricultural biodiversity and associated knowledge documented and } \\
\text { exchanged? }\end{array}$ \\
\hline (11) Women's knowledge & $\begin{array}{l}\text { Are women's knowledge, experiences, and skills recognized and } \\
\text { respected at household, community, and landscape levels? }\end{array}$ \\
\hline \multicolumn{2}{|l|}{ Governance and social equity } \\
\hline $\begin{array}{l}\text { (12) Rights in relation to land/ } \\
\text { water and other natural resource } \\
\text { management }\end{array}$ & $\begin{array}{l}\text { Does the community have customary and/or formally recognized rights } \\
\text { over land, (seasonal) pastures, water, and natural resources? }\end{array}$ \\
\hline $\begin{array}{l}\text { (13) Community-based landscape/ } \\
\text { seascape governance }\end{array}$ & $\begin{array}{l}\text { Is there a multistakeholder landscape/seascape platform or institution } \\
\text { able to effectively plan and manage landscape resources? }\end{array}$ \\
\hline $\begin{array}{l}\text { (14) Social capital in the form of } \\
\text { cooperation across the landscape/ } \\
\text { seascape }\end{array}$ & $\begin{array}{l}\text { Is there connection, coordination, and cooperation within and between } \\
\text { communities for the management of natural resources? }\end{array}$ \\
\hline $\begin{array}{l}\text { (15) Social equity, including gender } \\
\text { equity }\end{array}$ & $\begin{array}{l}\text { Is access to opportunities and resources fair and equitable for all } \\
\text { community members, including women, at household, community, and } \\
\text { landscape level? }\end{array}$ \\
\hline \multicolumn{2}{|l|}{ Livelihoods and well-being } \\
\hline (16) Socioeconomic infrastructure & $\begin{array}{l}\text { Is the socioeconomic infrastructure adequate for the needs of the } \\
\text { community? }\end{array}$ \\
\hline $\begin{array}{l}\text { (17) Human health and } \\
\text { environmental conditions }\end{array}$ & $\begin{array}{l}\text { What is the general health situation of local people also considering the } \\
\text { prevailing environmental conditions? }\end{array}$ \\
\hline (18) Income diversity & $\begin{array}{l}\text { Are households in the community involved in a variety of sustainable, } \\
\text { income-generating activities? }\end{array}$ \\
\hline (19) Biodiversity-based livelihoods & $\begin{array}{l}\text { Does the community develop innovative use of the local biodiversity for } \\
\text { its livelihoods? }\end{array}$ \\
\hline (20) Socioecological mobility & $\begin{array}{l}\text { Are households and communities able to move around between different } \\
\text { production activities and locations as necessary? }\end{array}$ \\
\hline
\end{tabular}


threats, and solutions. Finally, results are summarized to stimulate discussions on strengths and weaknesses in the SEPLS in order to develop potential action plans to improve SEPLS resilience. Facilitators and communities share results with key national stakeholders and policy makers so they can incorporate local landscape strategies into National Biodiversity Strategies and Action Plans and other development plans. The follow-up stage of the resilience assessment focuses on facilitating regular use of the indicators by community members as a means of monitoring SEPLS resilience to enable adaptive management.

Twenty countries participating in a large Satoyama program called COMDEKS (Community Development and Knowledge Management for the Satoyama Initiative) implemented by the United Nations Development Programme (UNDP) have used the indicators to conduct community-driven, participatory landscape planning; building on this exercise, communities have implemented their own projects to achieve the improvements in the landscape they wish to see. Bioversity International and partners have compared indicators field-tested in Kenya, Bolivia, and Nepal to identify the main drivers of change and resilience regarding the use and conservation of agricultural biodiversity in the context of climate change adaptation. The indicators proved helpful in reaching a common understanding of threats and solutions, and defining resilience-strengthening strategies. These examples from the field show that the indicators fill a gap in knowledge and that such tools at the local level are needed to enable communities to detect and monitor their social-ecological resilience. The indicators also help identify priority issues and actions for sustaining SEPLS that benefit livelihoods and well-being and create a common language between "traditional," "governmental," and "scientific" communities that addresses the complexity of human-environment interactions.

\section{Melanesian Well-Being Indicators: A Biocultural Approach}

\section{Jamie Tanguay}

The Melanesian Well-Being Indicators were developed in Vanuatu and designed for relevance across Melanesia, with outcomes focused on national-level assessments of human well-being. The people of Melanesia continue to depend on a traditional model of economic development that is self-contained and ensures equitable distribution of wealth and opportunity within a society. The "traditional economy," as it has come to be called in Vanuatu, is governed by shared cultural values and rules that dictate control over available resources (Regenvanu 2010). Unlike the economy valued in monetary terms, there are imposed limits to growth and wealth and defined roles for resource management. There remains, however, the challenge of measurement. Policies developed with regard only to increasing per capita GDP can have negative, and potentially disastrous, impacts on other factors contributing to life quality. The Melanesian Well-Being Indicators aim to assess and integrate consideration of this traditional economy with external indicators, enabling the island countries of Melanesia to develop in accordance with the shared values and expressed needs of their populations.

\section{Context of the Project}

The UN classifies the world's most impoverished countries as Least Developed Countries (LDCs). LDCs share low gross national income (GNI), weak human assets, and a high degree of economic vulnerability. Vanuatu is listed as an LDC with low GNI, a relatively small and undereducated labor force, and a high level of vulnerability to natural disasters (UN CDP 2017). Generally, LDCs face extreme poverty, ongoing and widespread conflict, extensive political corruption, and lack of political and social stability. However, this description generally does not apply to Oceania, where most LDCs are considered politically stable democracies that lack civil strife and have strong subsistence economies. 
In 2006, the UK-based New Economics Foundation published The Happy Planet Index: An Index of Human Well-Being and Environmental Impact, in which countries were ranked in relation to three indicators of well-being: life satisfaction, life expectancy, and ecological footprint (Marks et al. 2006). The report declared Vanuatu to be the "happiest country in the world." This finding was in contrast with the country's LDC status and brought forth awareness in the region of the desire to develop new indicators that take into account the income-neutral factors contributing to Melanesian well-being.

Three distinct dimensions of well-being were uncovered following social research undertaken by the Vanuatu National Statistics Office and the Vanuatu National Cultural Council involving focus groups and key informants. These dimensions include: (1) access to land and natural resources, (2) the skills to be productive with those resources, and (3) community vitality. Indicators were developed and piloted in Vanuatu in 2011 and 2012, and the Malvatumauri National Council of Chiefs launched the analysis report in 2012 (MNCC 2012).

\section{Biocultural Indicators of Land and Natural Resource Access}

The self-reliance of the Melanesian family unit is maintained only when access to, and power and control over, the land and its resources rests in the hands of clan or tribal leaders. Registration of land to individuals would lead to taxation and potentially shift people's priorities for the development of their customary land from providing for the collective unit to providing the individual with money. Melanesian societies treat land not as a personal commodity but as a public good. No one "owns" land in Melanesia; rather, families and individuals within the family unit are custodians of the land (Regenvanu 2008; Simo 2010). A variety of highly evolved and complex traditional land tenure systems exist in the region, which makes the survey and registration of customary land potentially harmful to traditionally sustainable collective livelihoods. The alternative biocultural indicators developed for land and natural resources do not focus on size or ownership but rather on accessibility and usage rights.

The biocultural indicators complement existing indicators collected through instruments such as the Agriculture Census and Household Income and Expenditure Survey, which seek to measure the economic productivity of land in terms of both income generation and, to a lesser degree, subsistence contributions. These alternatives, when presented alongside the more prevalent land-as-a-commodity indicators, provide decision makers with a better understanding of land and natural resource access. Specifically, they ascertain the proportion of Melanesians who enjoy free access to customary lands, how said access contributes to their livelihoods, and their assessment of the size of accessible land with respect to meeting basic needs. The Vanuatu well-being study-using an international standard for subjective well-being measurement as practiced by the Gallup World Poll, which asks participants to imagine their life quality relative to positioning on a 10-rung ladder (i.e., the Cantil Scale)-showed that those with access to customary lands are, on average, happier than those without (MNCC 2012).

\section{Biocultural Indicators of Traditional Knowledge and Production Skills}

Access to customary lands and natural resources provides the people of Melanesia with a means for life's basic necessities and connects them with their past and future. Decision makers must, then, also consider traditional knowledge transfer and the productive skills that are passed from one generation to the next as the ways in which resource access translates into tangible gains to life quality.

Melanesia is extraordinarily rich in its cultural diversity, with more than one thousand distinct Indigenous languages (Landweer and Unseth 2012). These Indigenous languages act as the major vessel of information and skills transfer from one generation to the next. A good measure of traditional knowledge in Melanesia must therefore consider the transfer and use 
of Indigenous languages, through indicators such as proportion of people whose first language was Indigenous and proportion reporting strong comprehension of and ability to speak the language (MNCC 2012). Cultural diversity brings with it diversity in how Melanesian societies use their natural resources. A particular food source considered a staple in one part of the region might be considered a supplementary food item in another. Traditional knowledge also varies with different skills of interest for different regions.

Composite indicators of traditional production skills reveal the proportion of the population that possesses some, all, or none of the elements chosen to comprise the indicators. In the Vanuatu study, for example, the five basic production skills included skills for making walls and roofing for housing, for food production and preparation, and for production of basic medicines. Furthermore, it was determined that all members of a household would benefit from just one member possessing each skill. Two-thirds of all households in Vanuatu were found to possess all five basic production skills (MNCC 2012). Providing decision makers with the proportion of the population that possesses the ways in which they can be productive with natural resources helps contextualize resource access in a meaningful way.

\section{Biocultural Indicators of Community Vitality}

Often in Melanesia, a village joins together for almost everything-from preparing land for planting, to repairing an old thatch roof, to nursing the sick and honoring the dead. The community is bound by, and depends on, cultural rules of reciprocity and respect. Indeed, even if an individual or family unit were capable of doing everything for themselves, they would not be inclined to turn down an offer of assistance out of respect, nor would they find it acceptable to be of no assistance to others in the community. A dimension of community vitality was included in the Melanesian Well-Being Indicators to capture the supportive role of the greater kinship networks and better reflect development as a collective achievement.

A strong community in Melanesia is one that works together to support its members. Community meetings are a common aspect in Melanesian society, bringing members together to discuss issues of common concern on a regular basis or for issues of urgency, when necessary. A sparsely attended meeting can be a sign of fragmentation or disunity within the community or a sign of weak leadership. For this reason, frequency of meetings and attendance levels are important indicators of community cooperation and respect for leadership (MNCC 2012).

A strong community in Melanesia is also one with able leaders who command respect and support from all community members. The symbiotic relationship between leaders and their communities is important, given that the majority of the region's population lives in rural villages governed by traditional leaders who represent the most effective means of information and service dissemination. It is important in Vanuatu that traditional leaders are good communicators, peacekeepers, resource managers, and vessels of culture and customary practices.

Finally, a strong community in Melanesia is one in which strong interpersonal networks thrive. Individuals with a strong social network have others they can rely on in times of need and neighbors they can trust. Strong families and kinship networks, built over generations, are also important considerations when determining the strength of social capital. Families-the single most important social alliance in Melanesia-are the building blocks of a strong community in the region.

\section{Biocultural Indicators Add Value to the Information Used in Decision Making}

The Melanesian Well-Being Indicators add value to the information used by decision makers when developing and assessing the human impacts of national policies. The value of these indicators can be realized only when they are officially recognized for their relevance to well-being in Melanesia and integrated alongside those indicators developed and adopted internationally. 
This integration has already taken place in Vanuatu, where the pilot report helped in creating a national development framework, which will inform national policy over the next 15 years. Additionally, some of the well-being indicators have been adopted as National Minimum Development Indicators by the Secretariat for the Pacific Community.

The purpose of these "alternatives" is not to establish a secondary set of measures but rather to incorporate Melanesian values-explicitly linked with their environments-into the indicators already in use by Melanesian decision makers. The Melanesian Well-Being Indicators will assist in building vision and a notion of greater interdependence in the region. Biocultural well-being indicators will also provide constructive feedback on the effectiveness of existing policies and programs, as well as useful input into program design and implementation. Thus, biocultural indicators, as evaluative tools, could be used not only to check whether programs are consistent with Melanesian well-being but also to foster a coherent relationship between professed values on the one hand and actual policies, programs, and projects on the other. If this process is done successfully, true Melanesian values will penetrate the region's economic, political, social, environmental, cultural, and technological development and bring a natural coherence to the region's policies.

In conclusion, the Melanesian Well-Being Indicators, once integrated in the region, promise to revive a broader understanding of an economy as a community managing its resources with a view to its productivity. The improved set of indicators will also more accurately present the welfare status of the people in the South Pacific. Access indicators for customary lands, forest and marine resources, and traditional wealth items, combined with indicators of traditional production skills and supportive social networks, form a uniquely Melanesian measure of self-reliance.

\section{The Cultural Basis of Well-Being in Peruvian Amazon Communities}

\section{Alaka Wali, Diana Alvira, and Ashwin Ravikumar}

This indicator set was developed in the Peruvian Amazon for application at the community level, with outcomes focused on well-being. An interdisciplinary team from the Field Museum in Chicago developed these indicators through an iterative action research process from 2001 to the present. The indicators are currently being used by the Field Museum team as part of ongoing quality-of-life plan development and implementation with communities in the Peruvian Amazon.

This case study describes incorporating a "biocultural perspective" into conservation efforts with Amazonian communities in Peru. Our data derives from rapid inventories (expert surveys of the geology and biodiversity of intact forests, paired with social assessments that identify natural resource use, social organization, cultural strengths, and the aspirations of local residents). The Field Museum Action Science team has conducted a total of 28 inventories since 1999, with 14 conducted in Peru's Department of Loreto, one of the most megadiverse regions of the world. The sites selected for inventories are determined through examining satellite images, conducting overflights, and organizing discussions with local conservation partners. The selection of communities for the social assessment relies on examining available demographic data, determining feasibility of access, and consulting with Indigenous organizations. Communities are comprised of Indigenous and long-term traditional forest dwellers, ranging in size from approximately 50 to 1,000 people (see Field Museum 2016a for long-term community-based work and 2016b for Rapid Inventory or RI reports; below we cite specific reports where the data can be accessed by report number). Additionally, we report here on data from longer-term efforts in the Peruvian Amazon involving 38 communities in the buffer zones of (1) the Cordillera Azul National Park, (2) the Ampiyacu-Apayacu Regional Conservation Area, and (3) the Sierra del Divisor National Park. In these landscapes, we collaborated with local NGOs and community 
residents to create quality-of-life plans that act as road maps for prioritizing actions to meet the needs and expectations of the population. The larger goal is to link the plans to local and regional stakeholders (Field Museum 2016a). The indicators we have developed with communities in the Peruvian Amazon are context-dependent, and the specific assets that emerged from this work describe the conditions of Amazonian communities. At the same time, the process that produced these indicators can be applied anywhere. For example, we have applied it in urban Chicago and the surrounding rural areas. The methodology for producing these indicators was developed by Field Museum social scientists working with Peruvian conservation professionals and social scientists and was field-tested with the participation of Indigenous organizations.

The assessment of cultural practices and worldviews (called "social and cultural assets") is the principal technique used to determine the degree of retention of cultural practices and beliefs that define the distinct Amazonian lifestyle (Wali 2016). Once the assessment, or "asset mapping" (Mapeo de Usos y Fortalezas, or MUF, in Spanish), is complete, it provides a rich data set from which indicators can be developed to measure well-being. The MUF is adapted from urban planning (Kretzmann and McKnight 1993; Wali et al. 2003). It is a combination of diagnostic instruments such as resource sketch mapping and participatory rapid appraisal using focus groups, household surveys, photo elicitation, and community meetings. By combining these systematically, we can provide a more comprehensive place-based assessment that integrates the identification of ecological knowledge, forms of social organization, and local institutional capacities (del Campo and Wali 2007; Wali 2016). Additionally, we use an interactive exerciseel hombre/la mujer del buen vivir-that allows people to rate their perceptions (on a scale of 1 to 5) of quality of life in five domains (natural resources, cultural practices, social relationships, governance or political processes, and household economics) and spurs discussion regarding the relationship between the environment and well-being (Wali et al. 2008). On this scale, a score of 1 represents the worst-case scenario (e.g., complete depletion of natural resources, total loss of Indigenous languages and cultural practices, paralyzing conflict within the community, authoritarian and nontransparent governance, and inability to meet basic needs), while a 5 represents the best-case scenario (e.g., abundant natural resources, strongly maintained Indigenous languages and cultural practices, harmonious social relations within the community, effective and legitimate local governance, and basic needs are amply met). Methods such as the creation of community crests, natural and cultural resource use maps, and the rating of perceptions of quality of life are useful for developing biocultural indicators in each of the five domains.

Our participatory research showed that Amazonian communities have mechanisms in place to regulate and protect resources linked to the extractive and subsistence economy. Participants mapped salt licks, lakes, and sites of mythical importance, as well as places where timber, fibers, medicinal plants, and fruits were harvested or cultivated. They provided a detailed analysis of the spatial patterns of biodiversity distribution. Participants also documented more deeply rooted systems of natural resource control embedded in mythological beliefs. For example, the Shawi, who live in the Cordillera Escalera (RI 26), believe in the power of a'shins (mothers), spirits that protect aspects of the natural world (Gow 1991). During the Ere-Campuya inventory and Tapiche Blanco inventories (RIs 25, 27), participants noted that some lakes are protected by madres (mothers) in the form of large snakes (boas or anacondas, likely Eunectes sp.) that discourage fisher people from visiting those lakes frequently. In each of these cases, shared beliefs encourage people to avoid overharvesting.

Traditional forms of social support such as communal work parties and other kinship-based systems of reciprocity also function to increase group productivity and well-being while protecting against overexploitation of the animals and plants in the forest. These cultural practices have been found in virtually all communities participating in the Peruvian inventories (RIs $11-12,16-18,20,22-28)$. 
Finally, these communities do not exist in isolation from other communities, broader Peruvian and global society, markets, and governance systems. Relationships that communities have with external actors also constitute key assets that they can leverage to improve their well-being, and these are documented and evaluated by communities and their allies.

In sum, our efforts in all these landscapes have demonstrated that both perceived and actual well-being status is relatively high. Only 9 of a total of 77 communities ranked their perception of quality of life at below a 3 during the el hombre/la mujer del buen vivir exercise. Generally, communities closer to healthier forest ecosystems rank their quality of life at a higher level (Figure 1). Perception correlates closely with actual well-being level measured in the integrated way of the MUF. While the indicators of well-being that emerge from the asset mapping process we have developed in the Peruvian Amazon fall into five domains (natural, social, cultural, economic, and political), any number of specific indicators can emerge in each of these domains. More important than the number of indicators identified in each domain is the interrelationship between these different dimensions of well-being. For example, forest resource stewardship is linked to cultural knowledge and to social relations that promote collective management.

The MUF-based measurement of well-being conflicts with the national characterization of these communities as living in extreme poverty (see Figure 1). Often in national develop-

Figure 1: Map of quality-of-life rankings on a scale of 1 to 5 averaged across communities in each protected area, overlaid on national map of poverty zones in Loreto, Peru.

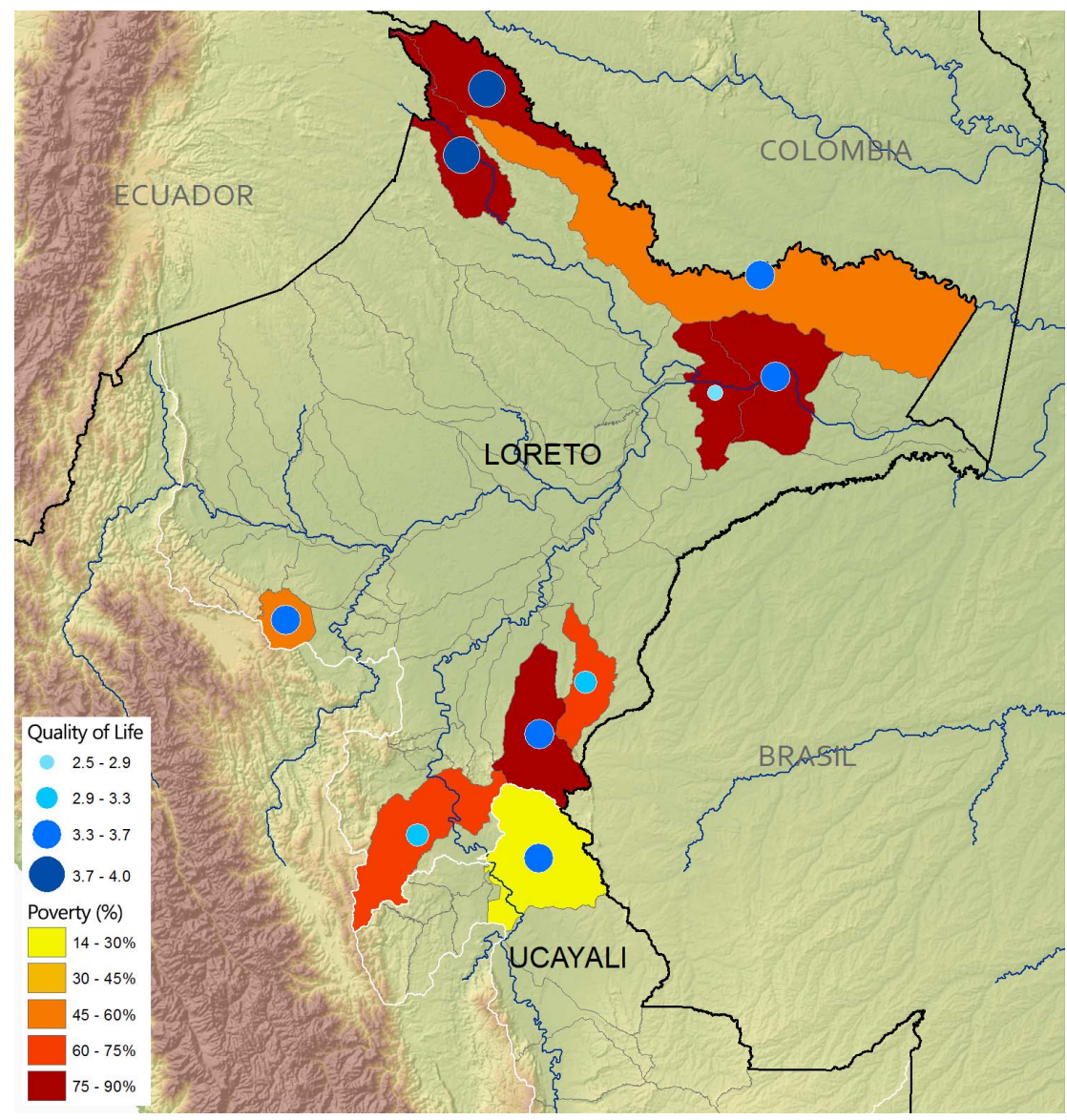

Source: Field Museum Conservation program. Poverty percentages at the district level from National Institute of Statistics, Government of Peru. 
ment discourses, "modernization" is equated as "progress" over forest-dwelling forms (Gasché Susess et al. 2010). Amazonian communities are constantly reminded of their "backward" status according to indicators such as per capita income, education level, and quality of infrastructure. Afforded the opportunity, they resist this characterization and retain values and practices that undergird their attachment to their homelands. As Peruvian anthropologist Alberto Chirif stated, "These indicators do not measure the quality of fresh foods Indigenous Peoples eat, the good air they breathe, the fresh water they drink from the streams, the happiness of the children playing in the rivers, or the control they feel over their own lives" (2007: 2-4).

Once people have used the indicators to reflect on their level of well-being, they set actionable priorities to improve their quality of life. In almost all cases, communities prioritize sustainable natural resource management alongside the maintenance of traditional practices in order to improve their well-being.

\section{Integrating Knowledge Systems to Innovate Community-Driven Approaches: Reestablishing Sustainable Relationships to Biocultural Land/Seascapes through Nā Kilo 'Āina, Hawai'i}

\section{Kanoe Morishige, Pelika Andrade, and Pua'ala Pascua}

This case study from Hawai'i encompasses the community level and can be applied crossculturally, with outcomes focused on social, cultural, and ecological health. The indicator set stems from a Native Hawaiian worldview and integrates Western scientific methods to characterize biocultural resilience in communities throughout Hawai'i. The tools and techniques presented in this approach, including seasonal and ecological indicators, are applicable in placebased and Indigenous communities across the globe.

In 2009, a small group of Native Hawaiian scholars at the University of Hawai' $i$ at Hilo developed the Nā Kilo 'Āina (NKA) program (Nā Kilo 'Āina 2014) and subsequent indicator set as a method to observe, internalize, and characterize biocultural systems. Understanding the essential role of Indigenous perspectives in conservation (Gadgil et al. 1993), the founding members-Native Hawaiians with strong cultural backgrounds and formal training in ecology-placed high value on integrating Indigenous and Western scientific knowledge through the NKA program. Since the first community partnership in Ka'ūpūlehu, Hawai'i Island, in 2009, NKA has expanded to communities across Hawai'i (including Kailapa, Hawai'i Island, and Hāena, Kaua ‘i) and beyond to Papahānaumokuākea Marine National Monument in the Northwest Hawaiian Islands. At present, the NKA program is formally housed under a nonprofit organization, Nā Maka o Papahānaumokuākea.

NKA captures community-level indicators to support community-driven management. Customarily, local-level resource management in Hawai'i supported thriving social and ecological communities (Ayers and Kittinger 2014; Friedlander et al. 2013; Tanaka 2008; Vaughan and Vitousek 2013; Vaughan et al. 2016). The term 'äina momona (literally: fat lands; figuratively: abundant and thriving sources of sustenance that support reciprocal relationships between people and place) is used to describe healthy and productive ecological, social, and cultural communities. Achieving 'äina momona is inherently a biocultural process involving local communities, scholars, and natural resource managers.

NKA engages participants in kilo (Native Hawaiian process of observation) by working through a series of seasonal indicators and numerous ecological indicators based on monitoring needs. Kilo is the act of observing but also refers to people who are adept observers and function as repositories of traditional and ecological knowledge to support a balanced and productive system (Maly and Pomroy-Maly 2003). The goal of NKA is to build the capacity of community 
kilo to (1) continue traditional knowledge systems, (2) understand both social and ecological communities, and (3) incorporate that knowledge in local resource management.

\section{Huli 'Ia: Seasonal Indicators}

Huli ' $\mathrm{Ia}$ is a facilitated process in which groups of participants characterize approximately 30 predefined indicators according to weekly or monthly observations (varying by project duration). The process has two main goals: (1) to identify dominant environmental patterns in the atmosphere, lands, and oceans-specifically how these events coincide and what they indicate; and (2) to build the capacity of the kilo to recognize and internalize these environmental observations. Example indicators include characterizing dominant weather patterns and indicating the presence and size of juvenile fish. The process also incorporates more nuanced indicators like scents of upland and coastal environments and reflections on physical and emotional wellness. Group observations are combed for dominant trends. At the conclusion, trends and linked occurrences are described through 'ólelo no'eau, Hawaiian proverbs that serve as vessels of Hawaiian knowledge. For example, after several years of monthly observations, participants in Ka'ūpūlehu noted that the beginning of Hooilo (wet season) is marked by the arrival of winter swells and upland rainfall, which forecasts the arrival of a highly prized seasonal intertidal algae, limu pāhe'e (Porphyra spp.). The 'ólelo no'eau composed to describe this relationship reads, "Ke pi'i nā nalu 'ulupā pōhaku, pulu ka papa a ulu ka pāhe'e. When the boulder-crashing waves arrive, the shelf becomes wet and limu pāhe'e grows."

\section{Ecological Indicators}

NKA includes marine ecological assessments in the kilo process. Knowledge of population health, life history, and reproductive life cycles are vital in the development of appropriate adaptive management tools (Poepoe et al. 2007). More importantly, sharing this knowledge may inform harvesting practices to avoid overharvesting and promote the long-term health of biocultural resources. Ecological indicators, including fish abundance and diversity of algae, are assessed with standard nearshore/intertidal monitoring techniques. Spawning potential is also determined for select species such as hä'uke'uke (Colobocentrotus atratus) and 'opihi (Cellana spp.). These methods characterize intertidal communities and quantify population dynamics over time. Integrating Huli ' $\mathrm{I} a$ and ecological monitoring methods characterizes times of peak spawning through the 'ōlelo no'eau, "Hō'ea mai o Lono i ka malu o ka lani, hoopuehu 'ia ke koa pa'a pohaku. At the arrival of Lono, god of fertility and peace, the rock-clinging invertebrates are spawning."

Results are presented back to communities by a method of their choosing. One deliverable from NKA's longest community partnership captures the integration of Huli 'Ia and ecological indicators at the scale of ahuриа' $a$ (watershed unit, from ridge to reef), or traditional land division in a seasonal calendar for Ka'ūpūlehu (see McMillen et al. 2016).

\section{Hawai i Conservation Alliance Community Watershed Snapshot: A Case Study of Local Measures for Ahupua'a Health}

\section{Lihla Noori, Christian Giardina, Manuel Mejia, and John Parks}

This case study encompasses the community level, with watershed health outcomes defined through a cultural lens and directed toward human well-being. The indicator set was developed for application to watersheds and communities of Hawai $i$, but we believe at least part of the set may be relevant across other locations and cultures, particularly within the Pacific Islands and other Small Island Developing States (Parks and Noori 2016). 
Native Hawaiian tradition interprets Hawai'i's natural environment through a cultural lens that recognizes the intimate physical, psychological, and spiritual relationship that Hawai'i's people have with their natural surroundings. The archipelago's natural wealth is not only valued for the ecological services that are provided to the people; it is also considered spiritually and genealogically connected to Hawaiians. Even today it is common to hear local residents speak of their ancestral connections to specific endemic flora and fauna, openly recognizing and behaving in ways that acknowledge and honor these connections. In this regard, it is the strength and the health of such biocultural connections between local families and their natural surroundings that are indicative of the health of the entire ecosystem, including humans.

The Hawai'i Conservation Alliance (HCA) is a cooperative collaboration of 24 natural resource conservation-related organizations representing state and federal agencies, educational institutions, and nonprofit organizations with a mission to provide unified leadership and action on conservation issues critical to Hawai'i. HCA's Effective Conservation Program (ECP) was conceptualized in 2003 to facilitate conservation of Hawai'i's native ecosystems in terrestrial, aquatic, and marine realms. In 2012, HCA ECP compiled available government agency geospatial data on their newly developed data-sharing platform with the intention to evaluate the status of natural resource management efforts across the islands, from mauka to makai (mountain to sea, aka "ridge to reef"). Evaluation was proposed at the watershed scale using metrics developed in consultation with interested communities and residents to elevate capacity of their own local management efforts.

Initiated in 2013, the Community Watershed Snapshot is an assessment-type status report on the health of watersheds, with twin goals of democratizing conservation and providing needed data for decision makers and communities. The snapshot combines geospatial data from government agencies with specific information gathered locally by volunteer communities and nongovernment partner organizations, including social-economic information and local küpuna (elder) knowledge. The goal is to generate relevant communication products on the current status of watershed health in support of local management efforts. A participatory process involving local communities and expert peer reviewers served to identify a set of high-priority biocultural indicators (Noori and Parks 2015). HCA consulted with local leaders and stakeholders from eight selected communities ${ }^{2}$ across the main Hawaiian Islands regarding their perceptions on how to measure the health of their own watershed through time. Out of these consultations, 80 community representatives identified a shared set of mauka (terrestrial), makai/wai (ocean/freshwater), and ka'ike (social-economic) factors that were important to the health of their ahupuai and were to be used to evaluate change in the current status of their snapshot (Noori and Parks 2015).

As a result of the consultative and collaborative process, in 2014 a set of 14 watershed snapshot metrics was endorsed by HCA. Ten of these indicators are biophysically focused (related to the quantity and quality of water, plant, and animal resources on land and in the ocean), whereas four are social-culturally focused. The latter include indicators of health, community involvement in natural resource management, and indicators of cultural well-being: number of and degree of respect for küpuna; number of families that obtain at least a portion of their sustenance from natural resources harvested within the land/seascape that they reside within; presence of traditional agriculture; and presence of traditional fishing practices (Noori and Parks 2015). The indicators are viewed through a social-ecological context. For example, "target food fish" rather than "keystone fish species," and "availability of freshwater" (for human use) rather than "volume/abundance of freshwater." All 14 indicators are framed using language that appeals to local communities and is considered "of highest importance" to them in terms of their utility in measuring the health of the watershed and natural surroundings that they reside 
within. In this regard, the indicators have not simply been "translated" for local use but rather by design have been identified and selected by Hawaiian communities as being of highest value, as validated through professional and scientific peer review and collaboration. In particular, the social-cultural indicators ( $\left.n a^{`} i k e\right)$ serve an important function in the context of assessing the health and resilience of natural systems in the Hawaiian Islands, in part because of the indicators being grounded under a Native Hawaiian value system that is based on public recognition of the social-ecological system, and focusing on the stewardship and sustainability of the system.

Under a standardized set of indicators, volunteer communities and partner groups throughout the main islands are measuring the health of their watersheds using selected metrics (Parks and Noori 2015, 2016). Despite initial concerns from participating communities regarding standardization and comparison between watersheds, there is now growing local interest to apply the standardized indicators to compare and contrast the status and trends of social-ecological health between and across Hawaiian watersheds, particularly for the purpose of learning from those watersheds that are performing better or have lessons to share (Parks and Noori 2016). By design, the indicator set is focused on place-based application, which is of interest to placebased decision makers involved in local management and development planning.

During 2015 and 2016, three communities volunteered to implement selected watershed snapshot metrics within their watersheds with the aim of using the information captured to inform and advance their local natural resource management efforts (Parks and Noori 2015). They engaged in the development, design, and production of communication tools to share their snapshot results locally, including through community-friendly posters, infographics, fact sheets, and slide presentations for national and international audiences. The three communities analyzed and documented their shared experiences and lessons in conducting their snapshots in order to begin engaging a long-term, community-based approach to assessing effective conservation of place, share lessons learned with other Hawaiian communities who also have an interest in initiating their own snapshot process, and integrate multiple knowledge systems and data sources in reactivating an intergenerational collaborative stewardship model that had defined how Hawai'i resources were managed prior to the advent of Western management approaches (Parks and Noori 2016).

Since the completion of the watershed snapshot communication products, the three volunteer communities have used their products to advance local management and engage elected officials (Parks and Noori 2016). During 2016 and early 2017, they documented and shared the results of their measures locally across multiple watersheds, and with federal, state, and nongovernment partners. Increasing demand from interested communities on how to participate in the snapshot process has led to the production of a practical, community-friendly guidebook, which helps readers to measure, document, and share their watershed snapshot indicators.

\section{Coming Together and Looking Forward in the Marshall Islands}

\section{Mark Stege, Tina Stege, and Jennifer Newell}

This case study encompasses the household and community levels and can be applied across the Marshall Islands, with outcomes focused on the health of landscape and seascape and community well-being. The process was developed in the Marshall Islands for use there. The barrier reefs that make up the Marshall Islands have been home for more than two millennia to a seafaring society and the site of intense challenges ranging from World War II battles, to decades of nuclear experiments, and now climate change. As dynamic and living geological features, the 29 atolls and five reef islands of the Marshall Islands need conservation action and stewardship to be resilient against the existential threat climate change poses to Marshallese culture and 
livelihoods. In response to climate and nonclimate stressors including plantation development, pollution, land clearing, increasing impact of commercial fisheries, and population growth, a team of government, nongovernment, and academic organizations-all with a common interest in the conservation, development, and management of the natural resources of the Marshall Islands-have developed the Reimaanlok Framework.

Reimaanlok (which means "looking forward") is an eight-step, community-driven process that focuses on the health of land- and seascape and community well-being (see Table 3). It is facilitated by the Coastal Management Advisory Council (CMAC), a national consortium that incorporates members from government ministries, agencies, NGOs, and academia. The Reimaanlok Framework is increasingly understood and practiced by CMAC members and has become mainstreamed within national government legislation, governance, and financing systems, most importantly within the Republic of Marshall Islands Protected Area Network and the Marshall Islands' commitment to achieve the Micronesia Challenge (MC) goal to effectively conserve no less than 30 percent of nearshore marine and 20 percent terrestrial areas in perpetuity. The aim is to "develop principles, processes, and guidelines for the design, establishment, and management of conservation areas that are fully owned, led, and endorsed by local communities based on their needs, values, and cultural heritage" (CMAC 2012: ii). For community leaders, Reimaanlok provides local cohesion amid a dizzying array of international development goals, regional commitments, national policies, and action plans.

When the Reimaanlok process is initiated by an atoll community's leadership (Step 1), a scoping and budgeting exercise (Step 2) ensues, followed by site visits by CMAC facilitators to build mutual awareness with the target atoll community on their community's specific needs for resource planning (Step 3) as well as the gathering and analysis of various parameters of social-economic, physical, and biological indicators of community well-being and ecosystem health (Step 4). During Steps 3 and 4, the CMAC consortium employs a mixture of tailor-made

Table 3: Summary of the Eight-Step Process for Community-Based Fisheries and Resource Management Planning

\begin{tabular}{|c|c|c|}
\hline \multicolumn{2}{|c|}{ Step } & \multirow{2}{*}{$\begin{array}{l}\text { Description } \\
\text { A need to develop a community-based resource management plan is } \\
\text { identified either at the local government level or at the national level. }\end{array}$} \\
\hline 1 & Initiation & \\
\hline 2 & Project scoping and setup & $\begin{array}{l}\text { Establish a project work plan, a team of facilitators, and identification of } \\
\text { budget and resources. }\end{array}$ \\
\hline 3 & Building commitment & $\begin{array}{l}\text { An initial visit is made by the national team to carry out education } \\
\text { awareness about the benefits of conservation and resource management, } \\
\text { and to build trust with the community. }\end{array}$ \\
\hline 4 & $\begin{array}{l}\text { Collecting and managing } \\
\text { information }\end{array}$ & $\begin{array}{l}\text { Further visits focus on collection and documentation of local knowledge } \\
\text { and use of resources, socioeconomic information, and baseline scientific } \\
\text { information. }\end{array}$ \\
\hline 5 & $\begin{array}{l}\text { Developing the } \\
\text { management plan }\end{array}$ & $\begin{array}{l}\text { Several visits are made to the community to develop, draft, and revise a } \\
\text { detailed management plan. }\end{array}$ \\
\hline 6 & Sign-off & Achieve commitment to the plan through sign-off of management plan. \\
\hline 7 & $\begin{array}{l}\text { Monitoring, evaluation, } \\
\text { and adaptive management }\end{array}$ & $\begin{array}{l}\text { Monitor achievement of the objectives-both biological and } \\
\text { socioeconomic. Adapt the management plan accordingly. }\end{array}$ \\
\hline 8 & Maintaining commitment & Ensure community has adequate support for ongoing management. \\
\hline
\end{tabular}

Source: CMAC (2012). 
and standardized tools based on evolving atoll science and best practices, which are generally contained within the Reimaanlok facilitator's guide (CMAC 2012). For instance, community knowledge and resource mapping is described under Appendix 8 of the guide, titled "Guidelines for the Collection of Local and Traditional Knowledge and mo in the Marshall Islands." This community resource mapping effort can be further enhanced with information based on the visual observations of the project team walking along a straight line across a specified cross-section of nearshore environment, as described in Appendices 9 ("Rapid Ecological Assessment, Participatory Aquatic Resource Transect") and 10 ("Baseline Rapid Assessment of the Natural Resources Methodology"). The guide also includes a comprehensive household survey (Appendix 12, "Socio-economic Baseline Assessment and Monitoring Plan Worksheet") heavily modified from the SEM-Pasifika (Wongbusakarum et al. 2008) to monitor well-being indicators including those on natural resource use, knowledge, and perceptions relevant to fishers, farmers, and handicraft trades, as well as overall climate change awareness and conservation effectiveness. Climate change impacts and adaptation are further assessed through a qualitative Vulnerability Assessment that relies on the knowledge of community members and subsequent development of a Local Early Action Plan (Appendix 35, "VA-LEAP"). High-resolution GPS surveys are used to determine island height and flood risk, complementing the VA-LEAP process (Appendices 13, "Developing Benchmarks Relative to Sea Level," and 14, "Surveying Island Height Procedures"). Quantitative surveys of natural resources are also conducted using standardized international protocols for marine and terrestrial resource assessments.

The information collected through Step 4 informs the development of a resource management plan (Step 5). Following on from the integrated, biocultural approach to data collection in Step 4, activities in this step include the development of both process and impact indicators to show, in the first case, the completion of processes/activities outlined in the resource management plan and, in the second case, the impact of management actions in a resource area. Impact indicators may be biological or social-economic (Appendix 23, "Developing Good Indicators"). While indicator development is driven by local concerns, the process is linked to national and regional initiatives like the Micronesia Challenge Socioeconomic Working Group, which identified the human well-being domains and attributes of the Micronesia Challenge and prioritized relevant indicators to measure the MC progress in achieving these attributes (Nevitt and Wongbusarakum 2013).

Steps 6 to 8 complete the process with sign-off on the management plan, monitoring and adaptive management of the plan's objectives (key to monitoring is the assessment of biological and social-economic indicators at regular intervals, as well as a review of the management plan every five years), and finally maintaining commitment to the plan through ongoing education, awareness, and capacity-building initiatives within the community. The process thus looks toward long-term dynamics and success.

Reimaanlok is recognized internationally as being at the forefront of contemporary coastal zone management and climate adaptation, particularly among Small Island Developing States where there is a paucity of scientific data and significant and increasing threats, and where decision making about the use of natural resources occurs primarily at the local level (Baker et al. 2011; Govan 2011; Grantham et al. 2011). Twenty-three atoll communities are currently engaged in some stage of the Reimaanlok process. Depending on where they are in the process, communities using this approach are experiencing various measures of success as they proceed in the step-by-step process of articulating threats and their needs and priorities, and codifying these into a management plan with various short-, medium-, and long-term measures, including enhancing their ecosystem and social-economic resilience to climate impacts. Six atoll communities are at Steps 6 or 7 of the process and thus have resource management 
plans in place to support informed conservation and sustainable development measures. For example, on Ailuk Atoll (Step 7) and Bikirin, Majuro Atoll (Step 6), these include windward vegetation planting projects, or jannar in Marshallese, to protect inland food sources and homesteads. Namdrik Atoll's (Step 6) engagement in the Reimaanlok process also informed planting projects, the establishment of a marine protected area, and the reactivation of a pearl farm. The Namdrik Atoll Local Resources Committee, a community organization constituted as part of the Reimaanlok process, received global recognition for its outstanding efforts in sustainable development at the Rio +20 United Nations Conference on Sustainable Development in Rio de Janeiro, Brazil, in 2012. The Reimaanlok process allows these municipalities/communities to stay engaged in implementing and monitoring conservation and sustainable development measures as a unifying endeavor for their community.

\section{Biocultural Approaches to Sustainability Indicators in Solomon Islands}

\section{Joe McCarter}

This case study reports on a biocultural approach to developing sustainability indicators in the Western Province of Solomon Islands (McCarter et al. forthcoming). The goal of this work is to support community-based resource management of land- and seascapes through the identification, assessment, and discussion of locally relevant sustainability indicators. The ongoing project seeks to link to provincial, national, and international sustainability assessments and to provide best practice lessons for using biocultural approaches in cross-cultural situations in Solomon Islands and elsewhere. The resulting indicator set addresses the household and community levels, and its outcomes focus on local resource management of land- and seascapes. The indicator set was developed for specific communities in Solomon Islands; however, indicator categories and trends have the potential to inform monitoring and evaluation in other contexts.

The Western Province of Solomon Islands is a unique mosaic of large lagoon systems and both high volcanic and small, coral-fringed islands. Nearly 80 percent of the population is rural, coastal, and relies on fishing and farming for nutrition and income (UN Data 2016). A number of pressures-from large-scale resource extraction to climatic variation-impact rural communities throughout the Western Province. While national legislation (e.g., the Protected Areas Act 2010) calls for environmental protection alongside appropriate "sustainable use," there is limited knowledge of how to measure and monitor such trends. This project works in four communities that differ in their degrees of market integration and ecological transformation but are all part of a community network maintained by the Solomon Islands Community Conservation Partnership (SICCP) and seek to strengthen or maintain systems for natural resource management.

The indicator set was developed to support sustainable community resource management around a range of social and ecological factors of importance to the communities. It explicitly sought to work across multiple domains and to make linkages between social and ecological components (e.g., between the success of gardens, health of community members, and degree of intactness of the terrestrial forest environment). We took a biocultural approach to indicator development, meaning we explicitly started with and built on place-based cultural perspectives-encompassing values, knowledge, and needs-and recognized the inextricable links between ecological and social realms (Sterling et al. forthcoming). Such approaches have the potential to strengthen the input of local voices in provincial, national, and regional forums, guide respectful engagement by NGOs and external researchers, and facilitate the development of multiple evidence-based approaches (cf. Tengö et al. 2014).

We began developing indicators by holding an initial set of workshops to explore community perceptions of current state, past trends, and ideal future visions. The outputs of these work- 
shops helped to define a set of domains that were important in each community. These domains included both ecological (e.g., integrity of forest) and social (e.g., degree of cooperation and unity) components, as well as linkages between them (e.g., maintaining vibrant vernacular language to communicate environmental information).

We used these domains to develop indicators, using an iterative process with communities. A draft indicator set was compared with regional and international examples and sorted according to theoretical frameworks (Folke et al. 2003). These various categorizing exercises underscored some differences between externally derived frameworks and local interests and perceptions, and in some instances the comparison helped to identify themes that might have been missed in the visioning process. For example, knowledge of systems limits-including Indigenous and Western scientific sources of information and practice-is critical to the ability to manage land and seascapes but did not explicitly emerge from the community visioning exercises and was added in (e.g., Foale 2006).

There are currently 68 indicators (62 quantitative and 6 qualitative) covering outcomes such as garden and ocean productivity, local knowledge regarding resource management, and state and trends of the environment, governance, and leadership. A subset of the indicators specifically addresses the feedbacks between humans and their environment; however, quantification of those indicators has been difficult.

We then worked with communities to collect data and assess the current state of the indicators. Data collection occurred over a period of 18 months. Data collection methods were designed and implemented in collaboration with community research assistants and comprised a variety of ecological and social science methods including structured interviews (e.g., dietary diversity, knowledge transmission), semistructured interviews (e.g., exploration of foodways and resilience), community surveys (e.g., catch per unit effort), and ecological survey methods (e.g., forest plotting, timed shellfish counts). Partner organizations or individuals provided expertise as needed. Data collection at all stages centered around training and capacity building, with the aim that community research assistants will be able to continue to collect data over the medium term. Indicator data overlapped but were not standardized across sites.

Data from the indicators were supported by other activities designed to stimulate discussion of landscape change over time. For example, participants in mapping "studios" compared large format aerial photos dating from the 1940s and 1960s against current high-resolution satellite imagery. Participants were also able to use the images to plan future change and explore tradeoffs (e.g., between agricultural expansion and village area).

Data were generally analyzed as they were collected, and reviewed with communities for comment and immediate discussion, sometimes in the context of targeted advice from expert advisers. For example, dietary diversity data were collected in November 2015 and May 2016, analyzed, and then discussed in communities with an expert team from the Ministry of Health and a local NGO (the Kastom Gaden Association). All data will be formed into two major products for use in communities: large-scale maps showing spatial and temporal aspects of landscape change and use, and indicator portfolios, or collections of stories and information from the various domains of data that have been collected. These products have been produced with a focus on durability and utility for planning and will feed directly into resource management planning at each site by partner organizations. Data analysis and production will be an iterative process; based on analyses and discussions with communities, there may be a call for further parsing or information collection.

The biocultural approach to indicator development outlined here may allow for the collection of social and ecological information for use by community decision makers but, importantly, also follows a process that allows for discussions within communities of current state and future 
planning. The outputs of this process can also offer place-based perspectives to policy makers in Solomon Islands, by highlighting components of resilience in the communities that are not commonly accounted for in national metrics. The importance and utility of the indicators over time will depend on their being effectively integrated into community and NGO programs, and on continued support to discuss and monitor into the future.

\section{Indicator Sets and Frameworks}

Many of the indicator sets described above were framed using existing conceptual frameworks (e.g., DPSIR, SES) that indicate how to convert data from indicators into decisions. However, decisions on the relevance of information and the selection of indicators and their relative importance can unintentionally introduce bias before any evaluation is undertaken. Thus, even when included through participatory processes, Indigenous indicators can be overwhelmed by the sheer scale of representation of other ways of knowing. The following framework foregrounds and quantifies different stakeholder worldviews to allow for comparison.

\section{Mauri Model Decision Making Framework}

\section{Tē Kipa Kepa Morgan}

Designed to be transparent, inclusive, and holistic, this framework identifies its ontological basis and provides an alternative Indigenous conceptual measure of sustainability. It is a unique approach to indicator set development that includes processes designed to ensure repeatability and objectivity in the evaluation being undertaken. The Mauri Model is intended for use at the community level and the process can be applied in any community, with outcomes focused on sustainability. Decision making frameworks based on systems thinking can facilitate enhanced understandings of sustainability and potentially enlighten societies to behave differently. In community settings, these frameworks must be contextually relevant and based on epistemological concepts that are more strongly aligned with sustainability (Morgan 2006a) than contemporary neoliberal capitalism (Di Tella and MacCulloch 2008). The epistemologies of Indigenous Peoples are commonly based on principles of interconnectedness, relevance over long periods of time, intergenerational equity, and uniqueness to place (Durie 2005). In the case of Aotearoa New Zealand, the Indigenous Māori have developed strategies to retain their values, beliefs, identity, and ways of being within a colonized societal context. For example, New Zealand law has been impacted by Māori claims relating to environmental degradation and retention of cultural values, knowledge, and language, often in terms of impacts on mauri, the life-supporting capacity of the ecosystem and its future potential (Morgan 2008). The Resource Management Act of 1991 aims to promote sustainable development, taking into account the environmental, social, cultural, and economic well-being of society. While the groundbreaking law incorporated numerous Indigenous concepts, it stopped short of actually including mauri.

A holistic and inclusive way to understand the world other than in monetary terms exists (Morgan 2008). Raymond Firth (1929) observed that mauri appeared to be the economic currency of traditional Māori society. Mauri is the binding force between the physical and everything else that makes life possible. It is the life-supporting capacity within a thing or collection of things such as an ecosystem. The concept can be likened to gravity, as while it may not be observable directly, it explains observable phenomena, being the force that when sufficiently diminished or denigrated defines the loss of potential to support life, or the difference between life and death. The Mauri Model Decision Making Framework was co-created with the Combined Tangata 
Whenua Forum and Ngāti Pikiao and Ngāi Tahu tribal entities (Morgan 2008), by inter-weaving Indigenous and scientific understandings of sustainability, specifically the Indigenous conceptualization of the mauri force and systems thinking (Morgan 2006a). As an expert-weighted decision matrix, the Mauri Model is holistic, simple to use, objective, and produces repeatable results. The Mauri Model is unique, as it provides a culturally neutral template within which Indigenous values are explicitly empowered alongside scientific data. Applications of the Mauri Model include many facets of impact assessment, encompassing treatment technologies, project sustainability, climate change adaptation, disaster response, and comparative studies. The Mauri Model combines a stakeholder worldview analysis with an indicator measurement process (Mauri Meter) to determine the absolute sustainability of the scenario being assessed, using mauri as the base metric. The concept of mauri is used to represent the potential of phenomena possessing physical and/or metaphysical characteristics. The capability to measure both physical quantities and metaphysical qualities allows for a wide, inclusive range of sustainability indicators that better reflect the physically, culturally, psychologically, and spiritually defined reality of Indigenous Peoples.

The Mauri Model has four constituent dimensions: mauri of the ecosystem, mauri of the Indigenous People, mauri of the community, and mauri of the base economic unit, the family or household. Adoption of these four dimensions facilitates more consistent comparison of impacts and effects across projects due to the ability to use the same metric to measure all indicators in a dimension and the constant groupings. Ecosystem indicators range from fertility of the land to water quality; cultural/ Indigenous indicators range from the use of traditional knowledge to heritage protection measures; community indicators range from access to community centers to life expectancy; and economic indicators range from employment availability to the price of energy.

The Mauri Meter defines the Likert scale used for measurement as five integers pivoting about zero (see Figure 2). Scores ranging from -2 to +2 depict possible states of mauri (negligible impact $=0$, partial impact $=1$, and full impact $=2$ ). A positive result reflects an impact that is sustainable. The Likert scale ensures objective assessment (see Figure 3) of indicators, as once the tolerance for a negligible indicator impact is defined (0 result), any other outcome is either sustainable (positive) or not (negative), and once the upper thresholds are defined for full impact $(-2$ and +2$)$, the absolute determination of sustainability is possible for each indicator. The combined result (arithmetic average) for a dimension reflects the overall trend occurring for that particular dimension. The combination of processes is shown in Figure 4. Dimension

Figure 2: Absolute indicator measurement using the Mauri Meter (after Morgan 2006b).

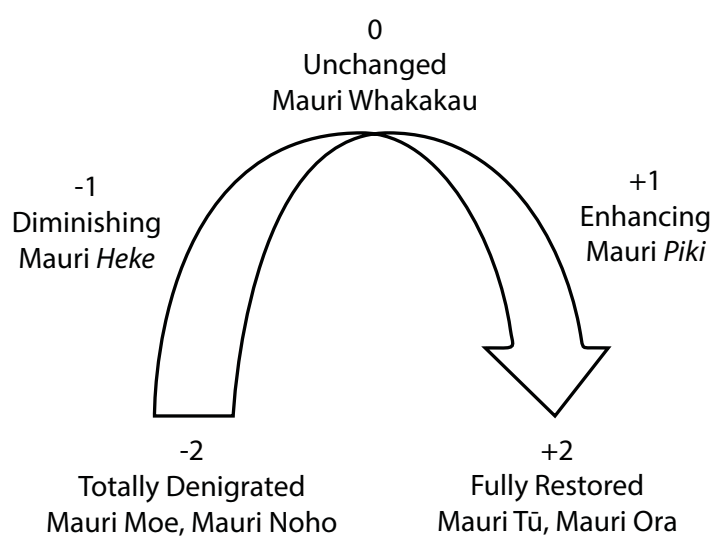

Figure 3: Decision tree eliminates partial scores ensuring minimum bias (Morgan et. al. 2012).

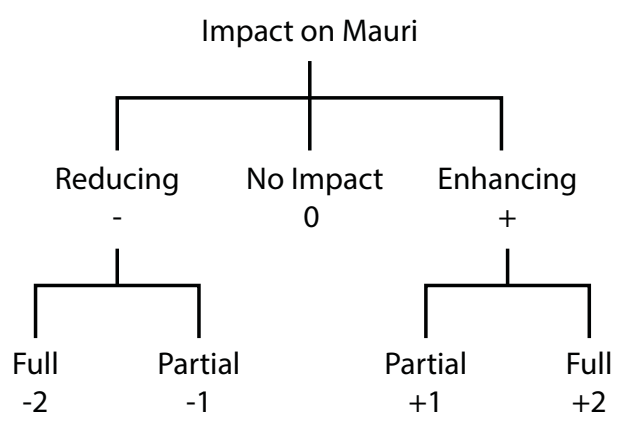


Figure 4: Mauri Model Decision Making Framework (after Morgan 2008).

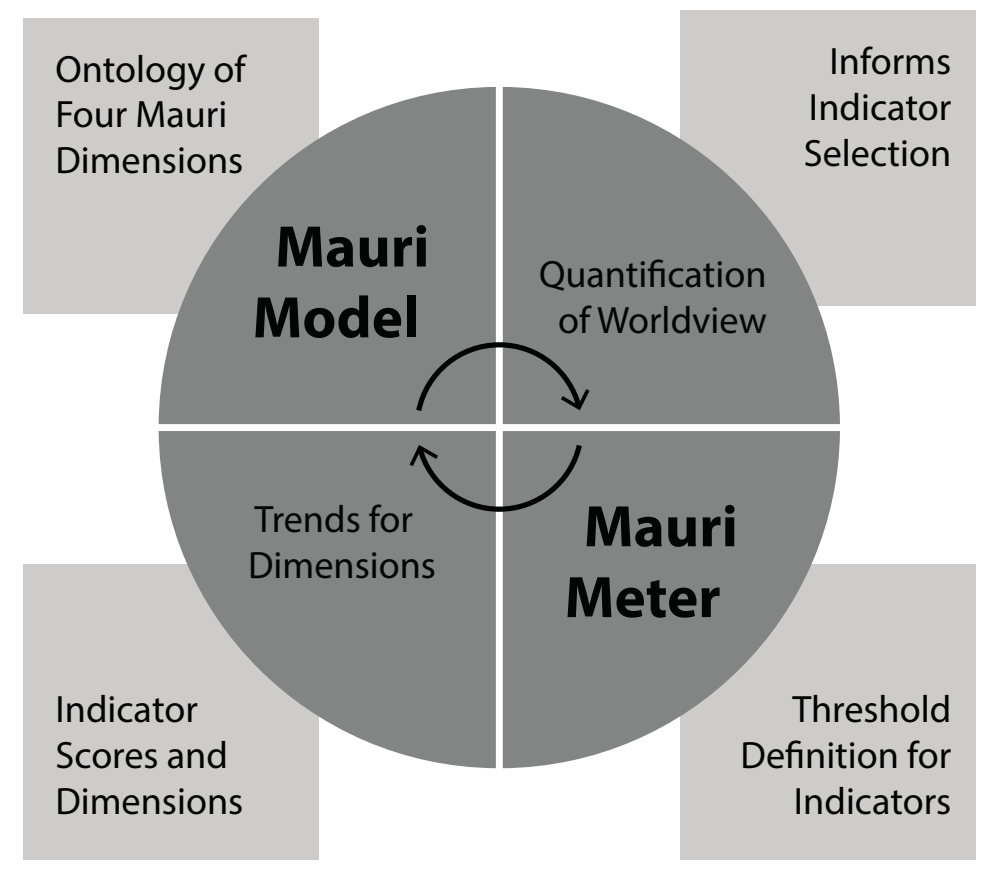

results can be depicted graphically as historic and future mauri trends when plotted against time on the horizontal axis (see Figure 5).

The Mauri Model also allows the quantification of different stakeholder worldviews, determining the relative priorities of the four mauri dimensions as percentage weightings using a pair-wise comparison technique (Saaty 1980). Accurate representation of adversarial perspectives of a situation without the need to alter actual mauri dimension results is an indication that the analysis will have credibility with the stakeholders that are impacted. The quantified priorities can reveal the inherent bias of stakeholders and also reflect the dimensions most strongly influencing a stakeholder's understanding of a situation. The Mauri Model has now been in use for more than a decade, taught as an engineering postgraduate elective at the University of Auckland for seven years and then digitized as a Web tool in 2012, and is the basis for assessments that quantify the impacts of New Zealand's worst environmental disaster, the oil spill from the 2011 grounding of the MV Rena (Fa'aui and Morgan 2014). Independent research determined the Mauri Model Decision Making Framework to be an exemplar sustainability indicator set when benchmarked against the Bellagio STAMP principles for sustainability, and concluded that the Mauri Model is relevant regardless of community (Challenger 2013).

The Mauri Model allows Indigenous Peoples to contribute understanding based on their own knowledge so that they can be effectively included in resource management decision making processes, with particular relevance to New Zealand law. The transferability of the Mauri Model identifies it as a potential pathway to more sustainable decisions and actions. Thus, through integrating systems techniques and the Indigenous concept of mauri, the Mauri Model creates a new approach to cross-cultural communication and action. As the Mauri Model is applied more broadly, some elements could be clarified to enhance its transferability in terms of impact on decision making. These include community issues related to governance and land rights, the feedbacks between mauri dimensions, the ability of the framework to capture short- and 
Figure 5: 100-year pre-Rena dimension trends for state of mauri (y-axis) plotted against distorted time intervals (x-axis) (Morgan et. al. 2015). The overall retrospective trend for mauri is presented as the equally weighted combination of the four dimensions.

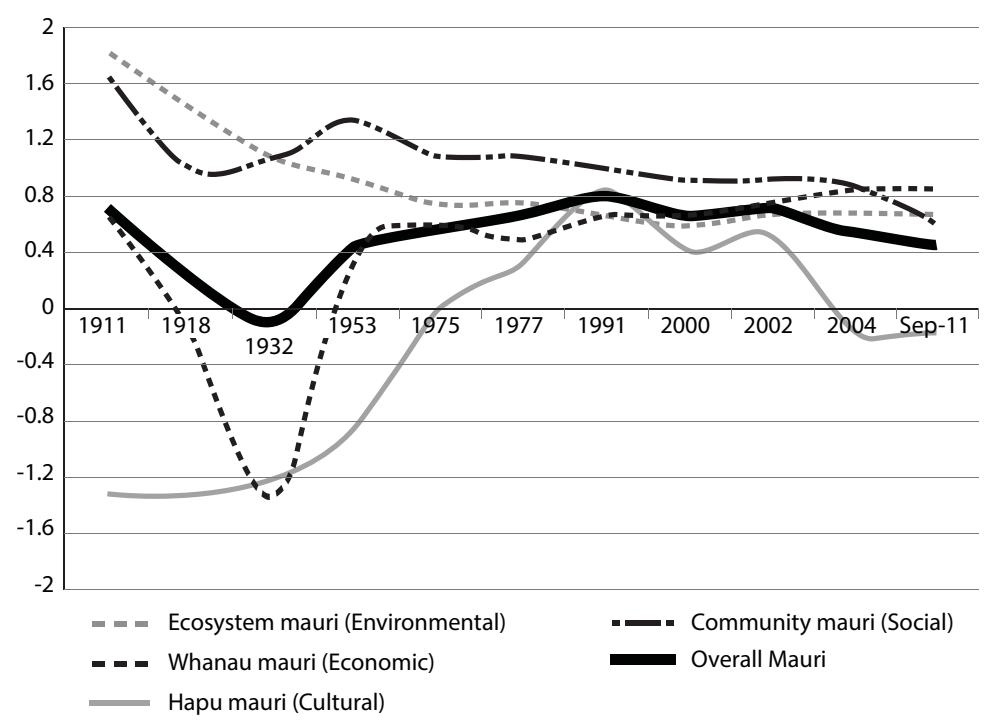

longer-term dynamics, and how quantified stakeholder worldviews can be weighted and translated into decisions.

\section{Discussion}

We present seven case studies and one framework to explore development of locally relevant and culturally grounded indicator sets assessing coupled social-ecological systems. Across case studies, we observe several common features that could help shape effective resilience indicator development and implementation (Table 4). We find that while the process of developing indicators varied among the case studies, all of them used an approach to developing indicators that can potentially be transferable to other places and/or cultural contexts, particularly within the geographic regions where they were developed.

Other commonalities include a reliance on multiple knowledge systems and mixed measurement systems (qualitative and quantitative), reflecting the importance of diverse sources of information. The case studies use a myriad of approaches for data collection, ranging from interviews to ecological survey methods. They include indicators that fall within four domains: social/cultural, economic, political/governance, and environmental. All of the approaches include indicators categorized as social/cultural, and well-being indicators that provide a more complex view of well-being than traditional metrics like GDP. A few case studies (Solomon Islands, SEPLS, NKA) also identified composite indicators that specifically measure feedbacks between different domains of the system; going forward, we see development of indicators that measure feedbacks as an important area for investment.

All case studies include indicators intended to support community decision making while providing information to policy makers or others in different contexts. Indicators were mostly collected and analyzed at the community and/or household level, though Melanesian WellBeing Indicators were planned, implemented, and analyzed at the national level. The case studies emphasize that insights provided by locally grounded approaches can be valuable to those 
Table 4: Characteristics of seven case studies and one framework: Socioecological Production Landscapes and Seascapes (SEPLS);

Melanesian Well-being Indicators (MWI); Peru; Nā Kilo 'Āina, Hawai'i (NKA); Hawai'i Conservation Alliance (HCA); Reimaanlok Framework, Marshall Islands; Solomon Islands; and the Mauri Model Decision-Making Framework, New Zealand ( 1 = applicable, $0=$ not applicable; V = variable).

\begin{tabular}{|c|c|c|c|c|c|c|c|c|c|}
\hline & & \multicolumn{8}{|c|}{ Cases } \\
\hline & & SEPLS & MWI & Peru & NKA & HCA & $\begin{array}{l}\text { Reimaanlok } \\
\text { Framework }\end{array}$ & $\begin{array}{c}\text { Solomon } \\
\text { Islands }\end{array}$ & $\begin{array}{l}\text { Mauri } \\
\text { Model }\end{array}$ \\
\hline \multicolumn{2}{|c|}{ Number of indicators } & 20 & $\mathrm{~V}$ & $\mathrm{~V}$ & $\sim 30$ & 14 & $\mathrm{~V}$ & 68 & $\mathrm{~V}$ \\
\hline \multicolumn{10}{|c|}{ General Characteristics } \\
\hline \multirow{4}{*}{ 鴶 } & Human well-being & 1 & 1 & 1 & 1 & 1 & 0 & 1 & 1 \\
\hline & Ecosystem well-being & 1 & 0 & 1 & 1 & 1 & 0 & 1 & 1 \\
\hline & Social-ecological approach & 1 & 0 & 1 & 1 & 1 & 1 & 1 & 1 \\
\hline & Sustainability & 1 & 0 & 0 & 1 & 1 & 1 & 1 & 1 \\
\hline \multirow{4}{*}{ 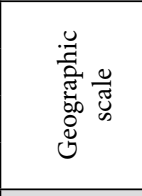 } & International & 0 & 0 & 0 & 0 & 0 & 0 & 0 & 1 \\
\hline & National & 0 & 1 & 0 & 0 & 0 & 1 & 1 & 1 \\
\hline & Community & 1 & 1 & 1 & 1 & 1 & 1 & 1 & 1 \\
\hline & Household & 1 & 1 & 1 & 1 & 1 & 1 & 1 & 1 \\
\hline \multirow{5}{*}{ 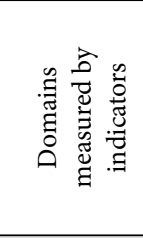 } & Environmental & 1 & 0 & 1 & 1 & 1 & 1 & 1 & 1 \\
\hline & \begin{tabular}{|l} 
Economic \\
\end{tabular} & 1 & 1 & 1 & 0 & 1 & 1 & 1 & 1 \\
\hline & Social/cultural & 1 & 1 & 1 & 1 & 1 & 1 & 1 & 1 \\
\hline & Political/governance & 1 & 1 & 1 & 0 & 1 & 0 & 1 & 1 \\
\hline & Interactions between domains & 1 & 1 & 1 & 1 & 1 & 1 & 1 & 1 \\
\hline \multirow{7}{*}{ 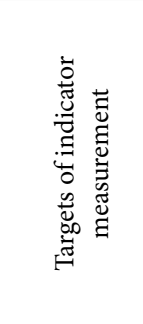 } & State & 1 & 1 & 1 & 1 & 1 & 1 & 1 & 1 \\
\hline & Trend & 1 & 1 & 0 & 1 & 1 & 1 & 1 & 1 \\
\hline & Pressures & 1 & 0 & 0 & 1 & 1 & 0 & 1 & 1 \\
\hline & Processes & 1 & 1 & 1 & 1 & 1 & 0 & 1 & 1 \\
\hline & Governance systems & 1 & 1 & 1 & 1 & 0 & 1 & 1 & 1 \\
\hline & Resource systems & 1 & 1 & 1 & 1 & 1 & 1 & 1 & 1 \\
\hline & Resource units & 0 & 1 & 1 & 1 & 1 & 0 & 1 & 0 \\
\hline
\end{tabular}




\begin{tabular}{|c|c|c|c|c|c|c|c|c|c|}
\hline & & \multicolumn{8}{|c|}{ Cases } \\
\hline & & SEPLS & MWI & Peru & NKA & $\mathrm{HCA}$ & $\begin{array}{l}\text { Reimaanlok } \\
\text { Framework }\end{array}$ & $\begin{array}{l}\text { Solomon } \\
\text { Islands }\end{array}$ & $\begin{array}{l}\text { Mauri } \\
\text { Model }\end{array}$ \\
\hline \multicolumn{10}{|c|}{ Indicator Use } \\
\hline \multirow{3}{*}{ 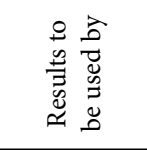 } & Policy makers & 1 & 1 & 1 & 1 & 1 & 1 & 1 & 1 \\
\hline & Academics/NGOs & 1 & 1 & 1 & 1 & 1 & 0 & 1 & 1 \\
\hline & Local stakeholders & 1 & 0 & 1 & 1 & 1 & 1 & 1 & 1 \\
\hline \multirow{6}{*}{ 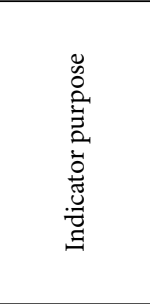 } & Influencing the public & 0 & 1 & 0 & 1 & 1 & 0 & 1 & 1 \\
\hline & Enhancing knowledge & 0 & 0 & 1 & 1 & 1 & 0 & 1 & 1 \\
\hline & Policy making & 1 & 1 & 0 & 1 & 1 & 1 & 1 & 1 \\
\hline & Local decision making & 1 & 1 & 1 & 1 & 1 & 1 & 1 & 1 \\
\hline & Assessment & 1 & 1 & 1 & 1 & 1 & 1 & 1 & 1 \\
\hline & Monitoring & 1 & 1 & 0 & 1 & 1 & 1 & 1 & 1 \\
\hline \multicolumn{10}{|c|}{ Methodological Characteristics } \\
\hline \multirow{3}{*}{ 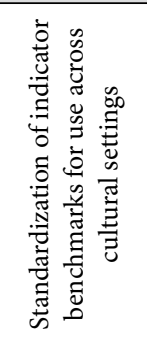 } & $\begin{array}{l}\text { No standardization-indicators meant for use } \\
\text { in only one setting, not comparative }\end{array}$ & 0 & 0 & 0 & 0 & 0 & 0 & 0 & 0 \\
\hline & $\begin{array}{l}\text { Yes, standardization cross-cultural (e.g., } \\
\text { criteria are meaningful in Peru and comparable } \\
\text { in Vanuatu) }\end{array}$ & 0 & 0 & 0 & 0 & 0 & 0 & 0 & 0 \\
\hline & $\begin{array}{l}\text { Yes, standardization culturally specific- } \\
\text { indicators standard but calibration culturally } \\
\text { specific }\end{array}$ & 1 & 1 & 1 & 1 & 1 & 1 & 1 & 1 \\
\hline \multirow{3}{*}{ 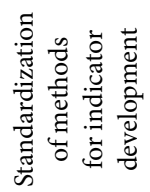 } & No standardization & 0 & 0 & 0 & 0 & 0 & 0 & 0 & 0 \\
\hline & Yes, standardization cross-cultural & 1 & 1 & 1 & 1 & 1 & 1 & 1 & 1 \\
\hline & Yes, standardization culturally specific & 0 & 1 & 0 & 1 & 1 & 1 & 1 & 1 \\
\hline
\end{tabular}


Table 4: continued

\begin{tabular}{|c|c|c|c|c|c|c|c|c|c|}
\hline & & \multicolumn{8}{|c|}{ Cases } \\
\hline & & SEPLS & MWI & Peru & NKA & HCA & $\begin{array}{l}\text { Reimaanlok } \\
\text { Framework }\end{array}$ & $\begin{array}{l}\text { Solomon } \\
\text { Islands }\end{array}$ & $\begin{array}{l}\text { Mauri } \\
\text { Model }\end{array}$ \\
\hline \multirow{3}{*}{ 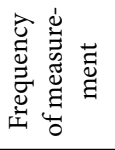 } & Annually & 0 & 0 & 0 & 0 & 0 & 0 & 0 & 0 \\
\hline & Only one snapshot to date & 0 & 1 & 1 & 0 & 1 & 1 & 0 & 0 \\
\hline & Other (including planned) & 1 & 1 & 0 & 1 & 1 & 1 & 1 & 1 \\
\hline \multirow{3}{*}{ 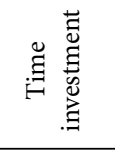 } & High investment (years) & 0 & 0 & 0 & 1 & 0 & 0 & 0 & 0 \\
\hline & Medium investment (months) & 0 & 1 & 1 & 0 & 1 & 1 & 1 & 1 \\
\hline & Low investment (day(s) or week) & 1 & 0 & 0 & 0 & 0 & 0 & 0 & 1 \\
\hline \multirow{3}{*}{ 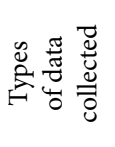 } & Perceptions only & 1 & 0 & 0 & 0 & 0 & 0 & 0 & 0 \\
\hline & Direct measurement only & 0 & 0 & 0 & 0 & 0 & 0 & 0 & 0 \\
\hline & Mix of perceptions and direct measurement & 0 & 1 & 1 & 1 & 1 & 1 & 1 & 1 \\
\hline \multirow{3}{*}{ 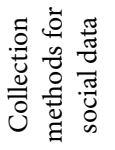 } & Focus groups & 1 & 1 & 1 & 1 & 1 & 1 & 1 & 1 \\
\hline & Household or individual surveys & 0 & 0 & 1 & 1 & 0 & 1 & 1 & 1 \\
\hline & Other & 0 & 0 & 1 & 0 & 1 & 1 & 1 & 1 \\
\hline
\end{tabular}


outside the community such as external researchers, policy makers, or NGOs. For instance, the indicators can help elucidate how communities contribute to the maintenance of biological diversity and ecosystems' ability to respond to stresses and change. In contributing to the development of a common language between local and external communities, the biocultural approach can enrich understanding of human-environment interactions. Policy makers can use the results as a decision support tool to identify benefits and consequences of actions, priorities, and sequences, and to develop strategies at the local and national level that are more consistent with local culture and values.

While there is variation across case studies in the total number of indicators, all case studies rely on disaggregated information versus a single index number. Disaggregated information requires a larger investment in interpretation or sharing information, whereas aggregated information (e.g., the social-ecological vulnerability index for coral reef-associated communities; see Cinner et al. 2013) can be quickly shared. However, disaggregated information may provide clearer insights into the factors moving a system in one direction or another. A single number can indicate what is happening but not why it is happening and may also mask different perspectives and viewpoints.

Scoring systems differ widely between case studies (though several cases score individual indicators on a five-point scale: SEPLS, Peru, Mauri Model). All indicator sets identify culturally relevant criteria to benchmark or standardize indicator scores, but some are more specific than others in setting these criteria. It is important to distinguish the process of developing indicators from the process of setting criteria used to determine where a community wants to be in relation to the indicator. Different communities might set different benchmarks and thresholds depending on their needs. Thus, standardization of indicators and related criteria for assessing the state of those indicators can inform action and policy and help communities to track changes through time, but the indicator and criteria do not have to be exactly the same across communities. Standardization can also help international agencies to identify where external input and resources can be useful to a community and facilitate allocation of resources across potential investments. Standardization of some form can allow for comparison across sites, giving communities access to potentially valuable information on how other communities react to similar situations. For example, the HCA case study describes how several communities have developed and shared communication products, such as posters and presentations, to facilitate exchange of lessons learned.

The majority of indicators were developed for communities to track what they believe is important, and are therefore tailored to a particular region and culture. Thus, the development of indicators and criteria for use at broader temporal or spatial scales than the community they stem from leads to a double-edged challenge. On one side, the indicator sets need to be specific enough to reflect the cultural and ecological contexts (and their links) of a given community; on the other side, lessons learned should be generalizable enough to allow for comparison across communities to trigger appropriate decision making in other contexts (such as national and international arenas). We note that this challenge can be negotiated in a number of ways, for instance, by developing an overarching conceptual framework and complementary indicator measurement processes within which individual communities can choose specific indicators and set locally relevant criteria (such as is done by the Mauri Model), by having general indicators whose criteria and specifics can be tailored to local settings (like SEPLS, though some challenges remain with comparable thresholds across sites), or by identifying some indicators within a set that are explicitly oriented toward comparison while having others that are locally tailored (Solomon Islands, Melanesian Well-Being Indicators, and Peru). Indicators developed for specific local contexts cannot be expected to serve as stable elements at other levels (Tsing 
2012), yet it is feasible to nest locally tailored indicators within targets that are comparable across geographies and to share cross-context lessons and not precise indicator measurements. Combining locally tailored metrics and broadly accepted standardized domains like wealth, health, and well-being (Donatuto et al. 2014) may provide scaffolding between locally tailored indicators and national or international metrics.

While all case studies illustrate the value and importance of using a biocultural approach to indicator development, there are many challenges, including those related to ensuring representation of diverse perspectives within heterogeneous communities when developing the indicators and/or ranking them; identifying ways to synthesize across results from the various indicators; potential costs, especially in terms of time commitments, which are often extensive with such an approach; and the feasibility of monitoring multiple indicators and how often they can or should be monitored to be meaningful. The acknowledgment of the potential for bias in models and frameworks is important, as is attention to design of tools to ensure the highest level of transparency about representation of values.

A particular challenge remains in how to operationalize regular assessment and to translate data into action. While many of the indicator sets we review are intended to influence local decision making, it is not clear how successful they have been in bringing about change. Future studies could focus on assessing whether or not taking a biocultural approach directly influences local policy and/or human behavior in ways judged as improving sustainability.

Frameworks that depict relationships and processes within systems can help move toward action via informing decision support tools. The Mauri Model weighs dimension outcomes within a matrix, allowing locally defined indicators to be meaningful and useable in real-world decisions. The Mauri Meter quantifies Indigenous values in a holistic and relatively simple way, thus making the indicators more useful than separate considerations that may be difficult to act upon. Janet Stephenson and Henrik Moller (2009) suggest that recognizing that science and Indigenous knowledge are founded in very different belief systems may open the way to resolving some of the tensions between them. While translation between worldviews and contexts is fraught (West 2005) and care must be taken with the integrity and robustness of the approaches developed, many of the case studies above demonstrate that bringing disparate types of knowledge into conversation has led to effective coproduction of new ways of knowing. Despite remaining challenges, current biocultural work has advanced efforts to represent a range of worldviews and values in measurements that facilitate understanding and management of complex systems.

\section{ACKNOWLEDGMENTS}

The material is based on work supported by the National Science Foundation (NSF) under grant nos. EF-1427091 and 1444184. Any opinions, findings, and conclusions or recommendations expressed in this material are those of the authors and do not necessarily reflect the views of the NSF. We received support from SNAPP (Science for Nature and People Partnership), a collaboration of the Nature Conservancy, the Wildlife Conservation Society, and the National Center for Ecological Analysis and Synthesis; the Gordon and Betty Moore Foundation; Lynette and Richard Jaffe; the Jaffe Family Foundation; and The Tiffany \& Co. Foundation. We thank Noelani Puniwai, Kainana Francisco, and Kekuhi Kanahele for their input; the Peruvian Amazon Indigenous and local communities and NGO and local government professionals and practitioners for their support and participation; Debby Moskovits, Corine Vriesendorp, and Paula Tallman at the Field Museum for their support; and anonymous reviewers and the editors for their thorough comments and constructive support. 


\section{AUTHORS}

Eleanor Sterling, Georgina Cullman, Erin Betley, Chris Filardi, Nadav Gazit, and Amanda Sigouin work at the Center for Biodiversity and Conservation, American Museum of Natural History. E-mail: sterling@amnh.org

Tè Kipa Kepa Morgan created the Mauri Model Decision Making Framework; various indicator sets have been developed using the framework by the author and others locally and internationally.

Diana Alvira, Ashwin Ravikumar, and Alaka Wali are part of an interdisciplinary team at the Field Museum that has worked to develop and implement the indicators described in their case study.

Pelika Andrade, Kanoe Morishige, and Pua'ala Pascua are Native Hawaiian scientists and community members from the University of Hawai i system who have helped to develop the NKA program and indicators.

Nadia Bergamini and Pablo Eyzaguirre are active collaborators in the development of the indicator set through the Satoyama Initiative and Bioversity International, and they have been testing the indicators through community focus group discussions in nine countries covering five different ecosystems.

Kate Burrows is a student at Yale University.

Sophie Caillon and Joachim Claudet work for the National Center for Scientific Research.

Rachel Dacks and Tamara Ticktin work at the University of Hawai'i at Mānoa.

Stacy Jupiter works for the Wildlife Conservation Society.

Kealohanuiopuna Kinney works at the Institute of Pacific Islands Forestry, United States Forest Service.

Joe McCarter works for the American Museum of Natural History (AMNH). The work in the Western Province of Solomon Islands is coordinated by the AMNH alongside its partners the Solomon Islands Community Conservation Partnership (SICCP), the Wildlife Conservation Society, and Ecological Solutions Solomon Islands.

Manuel Mejia, Christian Giardina, Lihla Noori, and John Parks led HCA's review, refinement, approval, and adoption of the finalized indicator set for application to watersheds and communities of Hawai' $i$. Noori led the HCA, which designed and supported the process. Parks and Noori convened and facilitated community focus groups at eight priority sites across the Hawaiian Islands to identify an indicator set through a community-based, participatory process. Giardina and Mejia use the indicator sets in their research and management daily.

Jamie Tanguay is the Coordinator for the Melanesian Well-Being Indicator initiative, hired by the government of Vanuatu under contract with the Vanuatu National Statistics Office since 2010. He facilitated a regional meeting and subsequent national focus group discussions on the contributing factors to Melanesian well-being and assisted in the development of the indicators based on output from social research.

Mark Stege (Marshall Islands Conservation Society and Coastal Management Advisory Council) has been directly involved in the development of indicators at site, national, and regional levels. Tina Stege (MarTina Corporation) and Jennifer Newell (Australian Museum) have worked with the CMAC to further inform indicator development by linking to other regional and international fora. 


\section{NOTES}

1. The authors comprise a collaborative network of community members, resource managers, other practitioners, government officials, and researchers from across the world working in the fields of sustainability, conservation, and anthropology. They are actively involved in a range of biocultural projects and initiatives, including indicator development. The article stems from a series of working groups aiming to identify, analyze, and compare frameworks and initiatives focused on offering place-based, culturally appropriate solutions to monitoring and evaluating for sustainability and well-being.

2. The eight participating communities (and home island) were (in order of consultation) Maunalua (O’ahu), Honolua/Napili (Maui), Hāena (Kauaii), Hanalei (Kaua'i), Kawela/Kakahaiáa (Moloka'i), Ka'ūpūlehu/Kīholo (Hawai'i), Hau'ula/Punalu'u (O’ahu), and Kīpahulu/Mūolea (Maui).

\section{REFERENCES}

Adger, W. Neil. 2000. “Social and Ecological Resilience: Are They Related?” Progress in Human Geography 24 (3): 347-364.

Ayers, Adam L., and John Kittinger. 2014. "Emergence of Co-management Governance for Hawai' $\mathrm{i}$ Coral Reef Fisheries." Global Environmental Change 28: 251-262.

Baker, Nicole, Maria Beger, Caleb McClennen, Albon Ishoda, and Florence Edwards. 2011. "Reimaanlok: A National Framework for Conservation Area Planning in the Marshall Islands." Journal of Marine Biology. doi:10.1155/2011/273034.

Béné, Christophe, Andrew Newsham, and Mark Davies. 2013. "Making the Most of Resilience." IDS In Focus Policy Briefings 32. http://www.ids.ac.uk/files/dmfile/IF32.pdf.

Challenger, Ian. 2013. A Process for Developing Sustainability Indicator Sets. Report No. 2224. Prepared for the Ministry of Business, Innovation and Employment. Nelson, NZ: Cawthorn Institute. $54 \mathrm{p}$.

Chirif, Alberto. 2007. Sistematización del Procesode Ejecución de los Proyectos de Reunificación, Revaloración Cultural y Continuidad del Puebl Secoya. Lima, Peru: IBIS.

Cinner, Joshua E., Cindy Huchery, Emily S. Darling, Austin T. Humphries, Nicholas A. J. Graham, Christina C. Hicks, Nadine Marshall, and Tim R. McClanahan. 2013. "Evaluating Social and Ecological Vulnerability of Coral Reef Fisheries to Climate Change." PLoS ONE 8. doi:10.1371/journal .pone.0074321.

CMAC (Coastal Management Advisory Council). 2012. Reimaanlok: An Approach for Community-Based Management-a Facilitator's Guide to Implementing the Reimaanlok Conservation Process. Honolulu: University of Hawai'i Sea Grant College Program.

Cochran, Patricia A. L., Catherine A. Marshall, Carmen Garcia-Downing, Elizabeth Kendall, Doris Cook, Laurie McCubbin, and Reva Mariah S. Gover. 2008. "Indigenous Ways of Knowing: Implications for Participatory Research and Community." American Journal of Public Health 98 (1): 22-27.

Colding, Johan, Thomas Elmqvist, and Per Olsson. 2003. "Living with Disturbance: Building Resilience in Social-Ecological Systems." In Navigating Social-Ecological Systems: Building Resilience for Complexity and Change, ed. Fikret Berkes, Johan Colding, and Carl Folke, 163-185. Cambridge: Cambridge University Press.

del Campo, Hillary, and Alaka Wali. 2007. "Applying Asset Mapping to Protected Area Planning and Management in the Cordillera Azul National Park, Peru." Ethnobotany Research and Applications 5: 25-36.

Di Tella, Rafael, and Robert MacCulloch. 2008. "Gross National Happiness as an Answer to the Easterlin Paradox?” Journal of Development Economics 86 (1): 22-42.

Donatuto, Jamie, Eric E. Grossman, John Konovsky, Sarah Grossman, and Larry W. Campbell. 2014. "Indigenous Community Health and Climate Change: Integrating Biophysical and Social Science Indicators." Coastal Management 42 (4): 355-373.

Durie, Mason. 2005. Ngā Tai Matatu: Tides of Māori Endurance. Melbourne, Australia: Oxford University Press. 
Ens, Emilie. 2012. "Conducting Two-Way Ecological Research." In People on Country: Vital Landscapes, Indigenous Futures, ed. Jon C. Altman and Sean Kerins, 45-64. Sydney: Federation Press.

Fa'aui, Tumanako Ngawhika, and Te Kipa Kepa Brian Morgan. 2014. "Restoring the Mauri to the Pre-MV Rena State." MAI Journal 3 (1): 3-17.

Fazey, Ioan, Nathalie Pettorelli, Jasper Kenter, Daniel Wagatora, and Daniel Schuett. 2011. "Maladaptive Trajectories of Change in Makira, Solomon Islands.” Global Environmental Change 21 (4): 1275-1289.

Field Museum. 2016a. "Conservation for Well Being." http://conservationforwellbeing.fieldmuseum.org (accessed 30 August 2016).

Field Museum. 2016b. "Rapid Biological Inventories." http://fm2.fieldmuseum.org/rbi (accessed 30 August 2016).

Firth, Raymond. 1929. Primitive Economics of the New Zealand Maori. New York: E. P. Dutton \& Co.

Foale, Simon. 2006. "Is Coral Reef Conservation Possible without Science Education in Melanesia? Is Science Education Possible without Development?" in Proceedings, 10th International Coral Reef Symposium, ed. Nicholas Polunin, Okinawa: Japanese Coral Reef Society.

Folke, Carl, Johan Colding, and Fikret Berkes. 2003. "Synthesis: Building Resilience and Adaptive Capacity in Social-Ecological Systems." In Navigating Social-Ecological Systems: Building Resilience for Complexity and Change, ed. Fikret Berkes, Johan Colding, and Carl Folke, 352-387. Cambridge: Cambridge University Press.

Friedlander, Alan, Janna Shackeroff, and John Kittinger. 2013. "Customary Marine Resource Knowledge and Use in Contemporary Hawai i." Pacific Science 67 (3): 441-460.

Gadgil, Madhav, Fikret Berkes, and Carl Folke. 1993. "Indigenous Knowledge for Biodiversity Conservation." Ambio 22 (2-3): 151-156.

Gasché Susess, Jorge, Napoleón Vela Mendoza, Erma Bablionia Cáceres, Julio César Vel Mendoza, and Wil de Jong. 2010. Sociedad Bosquesina: Tomo Ii. Iquitos, Peru: Instituto de Investigaciones de la Amazonia Peruana.

Govan, Hugh. 2011. Good Coastal Management Practices in the Pacific: Experiences from the Field. Apia, Samoa: Secretariat of the Pacific Regional Environment Programme. https://www.sprep.org/attach ments/Publications/GoodCoastMgtPacific.pdf.

Gow, Peter. 1991. Of Mixed Blood: Kinship and History in Peruvian Amazon. Oxford: Clarendon Press.

Grantham, Hedley S., Elizabeth McLeod, Anne-Marie Brooks, Stacy D. Jupiter, J. Hardcastle, Anthony J. Richardson, Elvira S. Poloczanska, et al. 2011. "Ecosystem-Based Adaptation in Marine Ecosystems of Tropical Oceania in Response to Climate Change." Pacific Conservation Biology 17 (3): 241-258.

Gu, Hongyan, and Suneetha M. Subramanian. 2012. Socio-Ecological Production Landscapes: Relevance to the Green Economy Agenda. Yokohama, Japan: United Nations University Institute of Advanced Studies.

Gunderson, Lance H., and Crawford S. Holling, eds. 2002. Panarchy: Understanding Transformations in Human and Natural Systems. Washington, DC: Island Press.

Kretzmann, John, and John McKnight. 1993. Building Communities from the Inside Out: A Path toward Finding and Mobilizing a Community's Assets. Chicago: ACTA Publications.

Landweer, M. Lynn, and Peter Unseth. 2012. "An Introduction to Language Use in Melanesia." International Journal of the Sociology of Language 214: 1-3.

Lebel, Louis, John Anderies, Bruce Campbell, Carl Folke, Steve Hatfield-Dodds, Terry Hughes, and James Wilson. 2006. "Governance and the Capacity to Manage Resilience in Regional SocialEcological Systems." Ecology and Society 11 (1): 19.

Maly, Kepa, and Onaona Pomroy-Maly. 2003. Ka Hana Lawai 'Aa Me Na Ko 'Ao Na Kai 'Ewalu: A History of Fishing Practices and Marine Fisheries of the Hawaiian Islands. HiPae74 (080103). Prepared for the Nature Conservancy. Hilo, Hawai'i: Kumu Pono Associates.

Marks, Nic, Saamah Abdallah, Andrew Simms, and Sam Thompson. 2006. The Happy Planet Index: An Index of Human Well-Being and Environmental Impact. London: New Economics Foundation.

McCarter, Joe, Eleanor J. Sterling, Stacy D. Jupiter, Georgina Cullman, Simon Albert, Marlene Basi, Erin Betley, et al. Forthcoming. "Biocultural Approaches to Indicator Development in the Solomon Islands." Ecology and Society. 
McMillen, Heather, Tamara Ticktin, and Hannah Kihalani Springer. 2016. "The Future Is Behind Us: Traditional Ecological Knowledge and Resilience over Time on Hawai'i Island." Regional Environmental Change 17 (2): 579-592.

Mijatović, Dunja, Frederik van Oudenhoven, Pablo Eyzaguirre, and Toby Hodgkin. 2013. "The Role of Agricultural Biodiversity in Strengthening Resilience to Climate Change: Towards an Analytical Framework." International Journal of Agricultural Sustainability 11 (2): 95-107.

MNCC (Malvatumauri National Council of Chiefs). 2012. Alternative Indicators of Well-being for Melanesia: Vanuatu Pilot Study Report. Port Vila, Vanuatu: MNCC.

Morgan, Te Kipa Kepa Brian. 2006a. "An Indigenous Perspective on Water Recycling." Desalination 187 (1): 127-136.

Morgan, Te Kipa Kepa Brian. 2006b. "Lifting the Lid on LID in Aotearoa NZ." Paper presented at the NZWWA Stormwater Conference, Rotorua, New Zealand, 4-5 May.

Morgan, Te Kipa Kepa Brian. 2008. "The Value of a Hapū Perspective to Municipal Water Management Practice: Mauri and Its Potential Contribution to Sustainability Decision Making in Aotearoa New Zealand." PhD diss., University of Auckland.

Morgan, Te Kipa Kepa Brian, Tumanako Ngawhika Fáaui, and Piatirihi Bennett. 2015. "Decision Support Systems: Just about Money or More Than That?” Paper presented at the 36th IAHR World Congress, The Hague, the Netherlands, 28 June to 3 July.

Morgan, Te Kipa Kepa Brian, Daniel N. Sardelic, and Amaria F. Waretini. 2012. "The Three Gorges Project: How Sustainable?” Journal of Hydrology 460-461: 1-12.

Nā Kilo ‘Āina. 2014. "Nā Kilo ‘Āina: Portal for Observers of Hawai'i Sustenance.” http://www.nakiloaina .com.

Nevitt, Brooke, and Supin Wongbusarakum. 2013. Indicators for Monitoring Social Impacts of Micronesia Challenge: An Addendum to Sem-Pasifika Socioeconomic Monitoring Guidelines for Coastal Managers in Pacific Island Countries. Pohnpei: Micronesia Conservation Trust.

Noori, Lihla, and John Parks. 2015. Community Watershed Snapshot Design Workshop Report. Honolulu: Hawai' i Conservation Alliance.

Olsson, Per, Carl Folke, and Thomas Hahn. 2004. "Social-Ecological Transformation for Ecosystem Management: The Development of Adaptive Co-Management of a Wetland Landscape in Southern Sweden." Ecology and Society 9 (4). https://www.ecologyandsociety.org/vol9/iss4/art2.

Ostrom, Elinor. 2009. "A General Framework for Analyzing Sustainability of Social-Ecological Systems." Science 325 (5939): 419-422.

Parks, John, and Lihla Noori. 2015. Effective Conservation Program Community Engagement Results. Honolulu: Hawai'i Conservation Alliance.

Parks, John, and Lihla Noori. 2016. Lessons Learned from the Community Watershed Snapshot Project. Honolulu: Hawai'i Conservation Alliance.

Poepoe, Kelson, Paul Bartram, and Alan Friedlander. 2007. "The Use of Traditional Hawaiian Knowledge in the Contemporary Management of Marine Resources." In Fishers' Knowledge in Fisheries Science and Management, ed. Nigel Haggan, Barbara Neis, and Ian G. Baird, 117-141. Paris: UNESCO.

Preuss, Karissa, and Madeline Dixon. 2012. "Looking After Country Two-Ways': Insights into Indigenous Community-Based Conservation from the Southern Tanami." Ecological Management and Restoration 13 (1): 2-15.

Regenvanu, Ralph. 2008. "Issues with Land Reform in Vanuatu." Journal of South Pacific Law 12 (1): 63-67.

Regenvanu, Ralph. 2010. “The Traditional Economy as Source of Resilience in Vanuatu.” In In Defence of Melanesian Customary Land, ed. Tim Anderson and Gary Lee, 30-33. Sydney: AidWatch.

Saaty, Thomas L. 1980. The Analytical Hierarchy Process: Planning, Priority Setting, Resource Allocation. New York: McGraw-Hill.

Simo, Joel. 2010. "Land and the Traditional Economy: 'Your Money, My Life' Hu I Kakae Long Basket Blong Laef?” In In Defence of Melanesian Customary Land, ed. Tim Anderson and Gary Lee, 40-44. Sydney: AidWatch. 
Sparks, Tim H., Stuart H. M. Butchart, Andrew Balmford, Leon Bennun, Damon Stanwell-Smith, Matt Walpole, Nicholas R. Bates, Bastian Bomhard, Graeme M. Buchanan, and Anna M. Chenery. 2011. "Linked Indicator Sets for Addressing Biodiversity Loss." Oryx 45 (3): 411-419.

Stephenson, Janet, and Henrik Moller. 2009. "Cross-Cultural Environmental Research and Management: Challenges and Progress." Journal of the Royal Society of New Zealand 39 (4): 139-149.

Sterling, Eleanor J., Christopher E. Filardi, Anne Toomey, Amanda Sigouin, Erin Betley, Nadav Gazit, Jennifer Newell, et al. Forthcoming. "Biocultural Approaches to Well-Being and Sustainability Indicators across Scales." Nature Ecology and Evolution.

Tanaka, W. 2008. "Hoohana Aku, Hoola Aku: First Steps to Averting the Tragedy of the Commons in Hawai'i’s Nearshore Fisheries." Asia-Pacific Law Policy Journal 10 (1): 235-291.

Tengö, Maria, Eduardo S. Brondizio, Thomas Elmqvist, Pernilla Malmer, and Marja Spierenburg. 2014. "Connecting Diverse Knowledge Systems for Enhanced Ecosystem Governance: The Multiple Evidence Base Approach.” Ambio 43 (5): 579-591.

Thaman, Randolph R., M. Meleisea, and J. Makasiale. 2002. "Agricultural Diversity and Traditional Knowledge as Insurance against Natural Disasters.” Pacific Health Dialog 9 (1): 76-85.

Tsing, Anna Lowenhaupt. 2012. "On Nonscalability: The Living World Is Not Amenable to PrecisionNested Scales." Common Knowledge 18 (3): 505-524.

UN CDP (United Nations Committee for Development Policy). 2017. "List of Least Developed Countries." Updated June 2017. https://www.un.org/development/desa/dpad/wp-content/uploads/ sites/45/publication/ldc_list.pdf.

UN (United Nations) Data. 2016. “Solomon Islands Country Profile." http://data.un.org/CountryProfile .aspx? crName=solomon\%20islands (accessed 1 September 2016).

UNU-IAS (United Nations University Institute for the Advances Study of Sustainability), Bioversity International, IGES (Institute for Global Environmental Strategies), and UNDP (United Nations Development Programme). 2014. Toolkit for the Indicators of Resilience in Socio-Ecological Production Landscapes and Seascapes. UNU-IAS, Bioversity International, UNDP-COMDEKS, and the Institute for Global Environmental Strategies (IGES).

van Oudenhoven, Frederik J. W., Dunja Mijatović, and Pablo B. Eyzaguirre. 2011. "Social-Ecological Indicators of Resilience in Agrarian and Natural Landscapes." Management of Environmental Quality: An International Journal 22 (2): 154-173. doi:doi:10.1108/14777831111113356.

Vaughan, Mehana Blaich, Barton Thompson, and Adam L. Ayers. 2016. "Pāwehe Ke Kai a 'O Hā 'Ena: Creating State Law Based on Customary Indigenous Norms of Coastal Management." Society and Natural Resources 30 (1): 31-46.

Vaughan, Mehana Blaich, and Peter M. Vitousek. 2013. "Mahele: Sustaining Communities through Small-Scale Inshore Fishery Catch and Sharing Networks." Pacific Science 67 (3): 329-344.

Wali, Alaka. 2016. "Contextualizing the Collection: Environmental Conservation and Quality of Life in the Buffer Zone of the Cordillera Azul National Park." In The Shipibo-Conibo: Culture and Collections in Context, ed. Alaka Wali and Claire Odland, 21-34. Chicago: Field Museum of Natural History.

Wali, Alaka, Gillian Darlow, Carol Fialkowski, Madeleine Tudor, Hilary Del Campo, and Douglas Stotz. 2003. "New Methodologies for Interdisciplinary Research and Action in an Urban Ecosystem in Chicago." Conservation Ecology 7 (3): 2.

Wali, Alaka, Mario Pariona, Teófilo Torres, Dora Ramírez, and Anselmo Sandoval. 2008. "Comunidades Humanas Visitadas: Fortalezas Sociales Y Uso De Recursos/Human Communities Visited: Social Assets and Use of Resources." In Ecuador, Perú: Cuyabeno-Güeppí. Rapid Biological Inventories Report 20, ed. William S. Alverson, Corine Vriesendorp, Álvaro Del Campo, Debra K. Moskovits, Douglas F. Stotz, Miryan García Donayre, and Luis Borbor, 111-121, 234-245. Chicago: Field Museum of Natural History.

West, Paige. 2005. "Translation, Value, and Space: Theorizing an Ethnographic and Engaged Environmental Anthropology." American Anthropologist 107 (4): 632-642.

Wongbusarakum, Supin, Robert S. Pomeroy, and Christen Eileen Loper. 2008. Sem-Pasifika: Socioeconomic Monitoring Guidelines for Coastal Managers in Pacific Island Countries. Apia: Secretariat of the Pacific Regional Environment Programme. 